\title{
Introjective and anaclitic psychopathology in self-narratives: Idiographic assessment with Hermans' Self-Confrontation Method
}

\author{
Rolf van Geel, Tilly Houtmans, and Hans Tenten
}

Department of Psychology, Netherlands Open University, Nijmegen, The Netherlands

\begin{abstract}
Within a hybrid framework of attachment and depression theory, we investigated whether introjective and anaclitic vulnerabilities can be detected in a person's self-narrative as elicited with the Self-Confrontation Method (SCM). One hundred participants held a thorough self-investigation with one of five trainees, in which every person formulated 'valuations' (i.e., short sentences about personally relevant concerns) and, subsequently, rated to what degree certain feelings were evoked by every separate text. We extracted several measures from these idiographic data, including scales representing the prominence of certain themes according to the SCM typology (e.g., 'unfulfilled longing and loss', 'anger and opposition', and 'powerlessness and isolation'). By analyzing the correlational patterns of the aggregated SCM-based measures and the questionnaire-based measures about attachment orientation and depressive personality vulnerability, we uncovered meaningful relationships. The results of a canonical correlational analysis indicated that an intensified sense of 'powerlessness and isolation' is a sign of a general psychopathological vulnerability (related to depression), 'anger and opposition' is associated with introjective features (distrust in others and need for control), and 'unfulfilled longing and loss' is associated with anaclitic features (pleasing and dependency). In an exploratory qualitative study, we used a cluster-based classification into attachment groups for the exhaustive screening of the content of negative valuations of (a selection of) insecurely attached persons $(n=15)$. This hermeneutic approach disclosed characteristic themes for each of the preoccupied, dismissive-avoidant and fearful-avoidant attachment styles which are discussed in great detail.
\end{abstract}

Keywords: adult attachment styles, depressive personality factors, agency, communion, psychotherapy

The Self-Confrontation Method (SCM), rooted in valuation theory, is a form of counselling in which themes of a person's self-narrative are identified and discussed in a profound dialogue (Hermans, 1976; 1981; Hermans \& Hermans-Jansen, 1995). The purpose of the SCM is to stimulate self-examination inducing the client to detect affective patterns in his/her story that reflect two 'latent' basic motives: (a) the striving for self-enhancement, and (b) the striving for contact and union. These strivings resemble the agentic and communal orientations as outlined by Bakan (1966), and they are common in a variety of theories and approaches in psychology (For a review, see Guisinger \& Blatt, 1994). McAdams (1994; cf. Bakan, 1966) defines agency as "the tendency to separate self from others, to master, dominate, and control the environment" (p. G-2), and communion as "the tendency to merge or unite with others, to surrender the self as part of a larger whole" (p. G-2). In Blatt's psychodynamic personality theory, normal development is conceptualized as the result of a reciprocal and dialectical interaction between two developmental lines: One that leads to a stable, realistic, and positive identity (the so-called introjective or self-definitional developmental line), and one that leads to satisfying intimate interpersonal relationships (the so-called

Correspondence to: Rolf van Geel, Department of Psychology; Netherlands Open University, P.O. Box 6870, 6503 GJ Nijmegen, The Netherlands. Tel.: +31-24-360-00-78

E-mail: Rolf.vanGeel@ou.nl anaclitic or relatedness developmental line) (Blatt, 1974; 2004; Blatt \& Shichman, 1983). These two developmental lines are very similar to the (agentic) striving for self-enhancement, and the (communal) longing for contact and union with the other, respectively.

An important result of the self-exploration with the SCM is that (positive and negative) themes associated with the basic motives become visible in the self-narrative. In general, the SCM-counselor should be attentive to the possible 'one-sidedness' of the self-narrative as a whole (the socalled 'valuation system') because this may indicate dysfunction. Like valuation theory, several other more prominent theories on psychopathology assume that for an optimal psychological functioning the fulfillment of both motivations is required, and that, correspondingly, psychopathology/dysfunction is (typically) the result of an overemphasis or exaggeration of one motivation at the expense of the other. In cognitive and psychodynamic depression theories two personality dimensions are assumed to make a person susceptible to depression and other psychopathologies (e.g., Mikulincer \& Shaver, 2007; Blatt, 2004). These vulnerabilities can be portrayed by (a) the excessive concern with interpersonal relationships, and (b) the one-sided investment in personal achievement (Blatt, 1974; Beck, 1983; Luyten, Blatt et al., 2005). In adult attachment theory two comparable higher-order personality dimensions are being distinguished: (a) the anxiety about rejection and abandonment, and (b) the avoidance of intimacy and discomfort with 
Table 1. Basic types of valuations and corresponding themes associated with levels of the Self $(\mathrm{S})$, Other $(\mathrm{O})$, Positive $(\mathrm{P})$, and Negative (N) scales

\begin{tabular}{cccccc}
\hline & \multicolumn{5}{c}{ Affective components of a valuation } \\
\cline { 2 - 5 } Types of & Self scale & $\begin{array}{c}\text { Other scale } \\
(\mathrm{O})\end{array}$ & $\begin{array}{c}\text { Positive scale } \\
(\mathrm{P})\end{array}$ & $\begin{array}{c}\text { Negative scale } \\
(\mathrm{N})\end{array}$ & \multicolumn{1}{c}{ Theme } \\
\hline Valuations & (S) & high & high & low & love and unity \\
$+\mathrm{O}$ & low & high & high & low & strength and unity \\
$+\mathrm{HH}$ & high & low & high & low & success, autonomy, perseverance \\
$+\mathrm{S}$ & high & low & low & high & aggression, anger, opposition \\
$-\mathrm{S}$ & high & low & low & high & powerlessness and isolation \\
$-\mathrm{LL}$ & low & high & low & high & unfulfilled longing, loss \\
$-\mathrm{O}$ & low & & & &
\end{tabular}

closeness (Brennan et al., 1998; Mikulincer \& Shaver, 2007; Bartholomew, 1990). These two risk factors for depression and insecure attachment are related to what in the literature is known as 'unmitigated communion' (the tendency to focus on others to the exclusion of self) and 'unmitigated agency' (the tendency to focus on self-development to the exclusion of others) (Helgeson, 1994). These theories consider psychopathology to be the result of a one-sided investment in either the striving for connection or the striving for self-definition, and neglect or defensive avoidance of the other (Luyten, Blatt et al., 2005). According to Mikulincer and Shaver (2007) attachment theory and Blatt's depression theory share a similar theoretical foundation, as expressed in the following citation: "attachment anxiety is related to interpersonal aspects of depression, such as overdependence, lack of autonomy, and neediness (the form of depression Blatt (1974) called anaclitic), avoidance is related to achievement-related aspects of depression such as perfectionism, self-punishment, and self-criticism (which Blatt called introjective depression)" (p. 379).

Blatt and Shichman (1983) state that introjective psychopathology is characterized by a neglect of development of satisfying interpersonal relationships and an extreme preoccupation with themes of identity, self-definition, selfworth, and self-control; the basic wish is to be acknowledged, respected, and admired. Kemmerer (2006) explains that "patients with introjective disorders are plagued by feelings of guilt, self-criticism, inferiority, and worthlessness. They tend to be more perfectionistic, duty-bound, and competitive individuals, who often feel like they have to compensate for failing to live up to the perceived expectations of others" (p. 6). Anaclitic psychopathology is indicated by the neglect of development of a sense of self, i.e., an excessive preoccupation with themes of closeness, intimacy, giving and receiving care, love, and sexuality; the basic wish is wanting to be loved (Blatt \& Shichman, 1983). Kemmerer (2006) clarifies that patients "with anaclitic disorders are plagued by feelings of helplessness and weakness; they have fears of being abandoned, and they have strong wishes to be cared for, protected, and loved" (p. 4).

In the present study, we investigated whether the introjective and anaclitic psychopathological features as described by adult attachment theory and depression theory can be detected in a person's self-narrative as elicited and recorded by the Self-Confrontation Method. Below, we first discuss the main features of this counseling method, in some detail, and explain how narrated personal experiences can be classified according to a typology. We then, briefly, focus on attachment and depression theory, and highlight Bartholomew's (1990) adult attachment prototypes in conjunction with the anaclitic and introjective depressive personality prototypes (Beck, 1983; Blatt, 1974). Finally, we elaborate on the similarities of the SCM-typology of narratives and the four attachment prototypes, which leads to the main objective of this study: to investigate what kind of features in a self-narrative may signal introjective and anaclitic (interpersonal) problems related to insecure attachment and depressive personality factors.

\section{The Self-Confrontation Method}

The purpose of the SCM is to foster self-examination concerning two 'latent' basic motives: (a) the striving for selfenhancement (the Self motive), and (b) the striving for contact and union (the Other motive). These strivings are expressed in the affective components of so-called 'valuations', the sentences a person formulates about important personal experiences from the past, present, or future. A valuation "can include a broad range of phenomena: a precious memory, a difficult problem, a beloved person, an unreachable goal, the anticipated death of a significant other, and so forth" (Hermans \& Hermans-Jansen, 1995, p. 15). Usually, a person's valuation system contains $30-40$ valuations. In order to provide a concise and clear picture of the affective side of a client's self-narrative, six types of valuations are being distinguished in the SCM. They represent basic experiences, associated with themes on a latent level, and are derived from the affective components of a valuation: the Self, Other, Positive and Negative scales. A description of the complete typology is given in Table 1. The Self (S) scale consists of indicators that express the striving for self-enhancement (e.g., self-confidence, strength). The Other $(\mathrm{O})$ scale includes feelings that reflect the striving for contact and union (e.g., love, tenderness). Feelings such as joy and happiness belong to the Positive $(\mathrm{P})$ affect scale, whereas feelings such as worry and unhappiness cover the Negative (N) affective domain. For every valuation a client rates the intensity of these affects on a 0-5 scale.

As represented in Table 1, the type of valuation is derived from the $\mathrm{S}-\mathrm{O}-\mathrm{P}-\mathrm{N}$ profile of affect scales. For example, the valuation "I consider it important to constantly learn new things, to be challenged intellectually, to be mentally on the move" $(\mathrm{S}=4.5, \mathrm{O}=0, \mathrm{P}=3.3, \mathrm{~N}=0)$ is indicated as 
Table 2. Examples of dysfunctional valuations

\begin{tabular}{|c|c|c|c|c|c|c|}
\hline Dysfunctional Theme & Type $^{a}$ & Valuation $^{\mathrm{b}}$ & $\mathrm{S}^{\mathrm{c}}$ & $\mathrm{O}$ & $\mathrm{P}$ & $\mathrm{N}$ \\
\hline Overdependence & $+\mathrm{O}(19 \%)$ & $\begin{array}{l}\text { It's nice to still be able to live at home, because my mother } \\
\text { can take care of me. I feel safe and secure at home. It is } \\
\text { also a peaceful place to study. }\end{array}$ & 1.8 & 3.3 & 3.8 & 0.5 \\
\hline Limitlessness & $+\mathrm{HH}(54 \%)$ & $\begin{array}{l}\text { My Faith gives me the Strength and Hope to fulfill all my } \\
\text { dreams and wishes. }\end{array}$ & 5.0 & 5.0 & 5.0 & 0.0 \\
\hline Grandiosity & $+\mathrm{S}(40 \%)$ & $\begin{array}{l}\text { I have always had a feeling of superiority; that I am } \\
\text { special, a strong belief in myself }\end{array}$ & 4.3 & 1.3 & 4.0 & 0.0 \\
\hline $\begin{array}{l}\text { Depression with self- } \\
\text { directed hostility }\end{array}$ & $-\mathrm{S}(19 \%)$ & $\begin{array}{l}\text { I think that I always have to be good at everything. } \\
\text { Otherwise, I feel inferior. }\end{array}$ & 1.3 & 0.0 & 0.3 & 2.5 \\
\hline $\begin{array}{l}\text { Hopelessness } \\
\text { and helplessness }\end{array}$ & $-\operatorname{LL}(33 \%)$ & $\begin{array}{l}\text { I often have difficulty finishing things off. I'm afraid of not } \\
\text { doing things well. I anticipate failure. }\end{array}$ & 0.8 & 0.0 & 0.0 & 3.8 \\
\hline Depressive grieving & $-\mathrm{O}(23 \%)$ & $\begin{array}{l}\text { I find it sad that I haven't been able to enjoy the good } \\
\text { things about student life in Amsterdam, because I was } \\
\text { feeling very mixed up. }\end{array}$ & 0.0 & 1.3 & 0.0 & 4.8 \\
\hline
\end{tabular}

Notes: ${ }^{a}$ Percentages of each of the six types per valuation system (of one person) are given in brackets; these illustrate the centrality of the kind of valuation in each valuation system. ${ }^{\mathrm{b}}$ These valuations were taken from the valuation systems of six people who perfomed a self-investigation with the first author in $1995 .{ }^{\mathrm{c}}$ The range of the $\mathrm{S}, \mathrm{O}, \mathrm{P}$, and $\mathrm{N}$ scales is $0-5$.

$\mathrm{a}+\mathrm{S}$ valuation, i.e., with more emphasis on $\mathrm{S}$ than on $\mathrm{O}(\mathrm{S}$ $>\mathrm{O})$ and with more positive than negative feelings $(\mathrm{P}>\mathrm{N})$, typically denoting an experience of 'success, autonomy and perseverance' (for specific guidelines, see method section of this study). For examples of the other types of valuations the reader is referred to Hermans and Hermans-Jansen (1995) and Van Geel (2000). An important result of the self-exploration with the SCM is that central themes become visible in the self-narrative. For example, a person may discover that the experience of 'love and unity' $(+O)$ is not contained in his/her valuation system because it is too threatening to his/her independence. He or she may then be stimulated to explore situations in which $+\mathrm{O}$ experiences have a greater chance of arising and to experiment with alternative behaviours. In general, the SCM counselor should be attentive to the possible 'one-sidedness' of a person's self-narrative as a whole, because this may indicate dysfunction.

The SCM is often applied in settings with people who have serious psychological problems. On the whole, these people tend to supply negative valuation types that dominate their narratives. According to the theory, dominance of one of the 'negative types' may exhibit 'depressive (or prolonged) grieving' $(-\mathrm{O})$, 'depression with self-directed hostility' (-S), or 'hopelessness and helplessness depression' (LL) (Hermans \& Hermans-Jansen, 1995). Such one-sided valuation systems are considered dysfunctional when the self-narrative "has become rigidly organized around one type of valuation and movement to other types of valuations is prohibited" (Hermans \& Hermans-Jansen, 1995, p. 154). It should be emphasized that it is not the dominance of negative types per se that makes a valuation system dysfunctional, but rather the accompanying restriction in thematic content of the narratives. Hence, a valuation system predominantly consisting of positive valuations might be considered dysfunctional as well. Dysfunctions related to the excessive presence of one of the positive types of valuations are indicated as 'grandiosity' $(+\mathrm{S})$, 'overdependence' $(+\mathrm{O})$, or 'limitlessness' $(+\mathrm{HH})$. Thus it seems that positive vs. negative feelings do not tell the whole story of mental health, as is expressed in the following citation: "The notion of flexibility is considered to be more essential to psychological health than a feeling of well-being $(\mathrm{P}>\mathrm{N})$. That is, a positive feeling of well-being is considered a relevant aspect of psychological health but it is not identical to it; positive development can be fostered by negative experiences" (Hermans \& Hermans-Jansen, 1995, p. 117).

In a healthy functioning system, various life experiences become integrated within the whole system of valuations, which leads to a diversity of valuation types. In a dysfunctional system important experiences are not wholly integrated or may even be excluded or dissociated from the narrative. For the purpose of illustration, Table 2 shows six dysfunctional valuations selected on the basis of the excessive relative presence of one of six types of valuations, positive and negative. They demonstrate the kind of content that may be expected in one-sided self-narratives.

The first valuation mentioned in Table 2 is given by a 19 -year old woman whose valuation system was, as compared to others, heavily loaded with 'unity and love' (19\% $+\mathrm{O})$. This valuation expresses a feeling of overdependence on her parents, which might be considered somewhat inappropriate given her age. The second valuation, which is of the $+\mathrm{HH}$ type, shows a rather dysfunctional content. The 'limitlessness', typical of the valuation system as a whole $(54 \%+\mathrm{HH})$, is found explicitly in the text of the valuation. The third valuation illustrates that in a system containing many valuations about 'success and autonomy' $(40 \%+\mathrm{S})$, it is likely that at least one of them will explicitly refer to the theme of 'grandiosity.' The stringent adherence to standards in the fourth $-\mathrm{S}$ valuation reflects a kind of self-directed hostility, which can become very dysfunctional indeed. The fifth valuation documents a dysfunctional property of -LL, viz., generalized powerlessness, a characteristic of 'hopelessness depression' (Hermans \& Hermans-Jansen, 1995). Finally, the $-\mathrm{O}$ valuation captures the intense grief associated with the long-term absence of joy during adolescence. These six examples illustrate that in one-sided valuation systems some valuations may explicitly point to the dysfunction involved.

It should be noted that dysfunctional aspects may go unnoticed when a person (un)consciously excludes important experiences from his/her self-narrative. Sometimes so- 
called 'distortions' are observable in a text that expresses either a distinct longing for union or a conspicuous striving for independence without associating this text with the typical affect terms. Take, for example, the following text of a middle-aged man, who formulated many $-\mathrm{O}$ valuations: "If I have to study texts which pretend to be scientific, but which do not meet requirements of carefulness, I experience a feeling of aggression which is expressed in a respectable intellectual way" $(\mathrm{S}=0.5, \mathrm{O}=2.5, \mathrm{P}=0.5, \mathrm{~N}=3.0)$. This $\mathrm{O}$ valuation concerns a feeling of irritation related to doing editing work for colleagues, but, instead of expressing his anger $(-\mathrm{S})$, he responds with a longing for contact. This person seems incapable of expressing his anger where it would be appropriate to do so (For other examples, see Van Geel, 2000). Dissociations in general belong to the self-organizations of many people in ordinary life. However, when they are excessively in charge, the omission or distortion of personally relevant experiences may result in a dysfunction of the self (Hermans \& Hermans-Jansen, 1995).

\section{Introjective and anaclitic psychopathology}

In Blatt's (1974) psychodynamic and Beck's (1983) cognitive depression theory two comparable personality dimensions predisposing to psychopathology can be distinguished. The first - 'introjective'- personality dimension refers to distorted attempts to exercise control and maintain self-esteem, reflecting an excessive investment in personal achievement, excessive demands for accomplishment and control, and relentless self-criticism when stringent selfstandards are not met, labelled as Self-criticism (Blatt, 1974) and Autonomy (Beck, 1983). This may result in a self-critical or introjective depression, involving "self-criticism, guilt, shame, worthlessness, and often a chronic fear of being criticized or disapproved" (Luyten, Blatt et al., 2005, p. 79). The second -'anaclitic'- personality dimension refers to distorted and intensified attempts for connection, reflecting an excessive reliance on and investment in significant others, as well as intense needs for acceptance and love from others, labelled as Dependency (Blatt, 1974) and Sociotropy (Beck, 1983). This may lead to a dependency- or anaclitic depression, which is "characterized by feelings of loneliness, helplessness, weakness and fears of abandonment" (Luyten, Blatt et al., 2005, p. 76). These two personality dimensions, identified by Blatt and Beck, are very similar to dimensions originating from adult attachment theory (Mikulincer \& Shaver, 2007; Luyten \& Blatt, 2012).

Research on adult attachment relationships suggests that 'attachment avoidance' and 'attachment anxiety' are crucial dimensions, which underlie four basic attachment prototypes (Brennan et al., 1998; Mikulincer \& Shaver, 2007). The avoidance dimension refers to discomfort with closeness and dependency, distancing from others and denial of attachment needs, whereas the anxiety dimension refers to the oversensitivity to clues about abandonment, separation, and rejection, and an exaggerated need for reassurance, attention, and support (Brennan et al., 1998). Mikulincer and Shaver (2007) proposed that these two dimensions reveal two different strategies to deal with insecurity and distress when a security-providing attachment figure is unavailable or unresponsive: The avoidant (or deactivating) attachment strategy involves "denying attachment needs and asserting one's own autonomy, independence, and strength" (Luyten \& Blatt, 2012, p. 116); the anxious (or hyperactivating) attachment strategy is characterized by “(...) frantic attempts to find security, support, and relief, often expressed in demanding or clingy behavior" (Luyten \& Blatt, 2012, p. 116). Bartholomew (1990) developed a model of four attachment prototypes based on the (orthogonal) dimensions of anxiety and avoidance: secure, preoccupied, dismissing, and fearful. People with a secure attachment style don't worry about not being accepted by others (they display low anxiety) and easily get emotionally close to others (they display low avoidance). People with a preoccupied attachment style exhibit 'an insatiable desire to gain others' approval and a deep seated feeling of unworthiness" (p. 163). Hence, they display a strong desire for emotionally intimate relationships (low avoidance), but at the same time they worry about not being accepted by others (high anxiety). People with a dismissing avoidant style defensively deny the need for intimacy (high avoidance) in order to preserve a sense of selfsufficiency and invulnerability (low anxiety); people with a fearful avoidant style, on the other hand, shun intimacy (high avoidance) in order to avoid the pain of potential loss or rejection (high anxiety), without really relinquishing their desire for acceptance and support from others.

Van Geel et al. (2016) studied the features of attachment theory and the depression theories of Blatt and Beck in detail, and concluded the following (p.54): "The global picture that emerges (...) is that the two higher-order depressive personality styles are associated with the two higher-order attachment dimensions. A crucial interpersonal problem associated with attachment anxiety and sociotropy/dependency seems being overly friendly and non-assertive, representing an inability to express anger towards others or to stand up for oneself for fear of rejection. A critical feature of attachment avoidance as well as autonomy/self-criticism seems interpersonal coldness, representing a tendency to distance oneself from others. Regarding the prototypes, anaclitic personality and preoccupied attachment are very much alike, whereas Blatt's concept of Self-Criticism appears to have more in common with the fearful-avoidant attachment style than with the dismissive-avoidant attachment style. According to Luyten, Corveleyn, et al. (2005), Beck's Autonomy concept seems more closely related to the dismissive-avoidant attachment style, reflecting a distinctive theoretical view. Beck emphasized the distancing from others and aloofness in autonomous individuals, whereas Blatt maintained that introjective individuals desire contact with others, and although fearing criticism, also need the approval of others (Luyten, Corveleyn, et al., 2005)."

Van Geel et al. (2016) examined the factorial structure of a combined set of items about adult attachment orientation and depressive personality vulnerabilities in a large sample of (for the most part) university students $(N=1,189)$. By employing exploratory and confirmatory factor analysis in two samples, they uncovered three higher-order dimensions: (I) Attachment Anxiety: (a) Concern what Others Think, (b) Pleasing, (c) Dependency/Difficulty with Being Alone; (II) Attachment Avoidance: (a) Avoidance of Intimacy, (b) Lack of Trust; and (III) Need for Control and Independence. In the present study we will also use the 
(sub)scales of this Anxiety-Avoidance-Control model (AAC model), as these transparently portray the different interpersonal problems of the insecure attachment prototypes, as well as the anaclitic and introjective personality types. Clearly, Attachment Anxiety can be conceived of as an anaclitic vulnerability factor for depression and other psychopathologies, and Attachment Avoidance and Need for Control can be regarded as introjective vulnerability factors (For a discussion, see Hopwood, Mulay, \& Waugh, 2019).

As discussed above, all the theories referred to share the notion that psychopathology originates from the inflexible one-sided investment in either the striving for connection or the striving for self-definition. This notion has prompted researchers to investigate the links with personality disorders. Brennan and Shaver (1998) studied the links between selfreported attachment style and self-reported personality disorders in a group of introductory psychology students $(N=$ 1,407). Preoccupied attachment seemed to be associated with dependent and histrionic personality traits. Dismissiveavoidant attachment was associated specifically with schizoid personality disorder, whereas the fearful-avoidant attachment style was associated with a range of problematic features, including worries about being abandoned (borderline personality disorder), being rejected (avoidant personality disorder), and being harmed by others (paranoid personality disorder). Ouimette, Klein, Anderson, Riso, and Lizardi (1994) correlated self-reported depressive personality dimensions with interview-based Axis II traits in a group of out-patients diagnosed with depression or personality disorder $(N=138)$. Dependency and sociotropy were uniquely associated with dependent and histrionic personality traits. Self-criticism and autonomy were associated with a wide range of traits, including those related to schizoid, paranoid, and narcissistic personality. Borderline personality traits were associated with all four depressive personality scales, but uniquely with self-criticism and autonomy, suggesting that this personality disorder belongs to the introjective psychopathology cluster. The findings of Ouimette et al. (1994) further suggest that schizoid personality involves pure introjective psychopathology (cf. dismissive-avoidant attachment), but that avoidant personality involves a mix of anaclitic and introjective features (cf. fearful-avoidant attachment). To summarize, although the empirical findings are not very consistent, it seems that there are connections between preoccupied attachment and dependent and histrionic personality disorder; between dismissive-avoidant attachment and schizoid, anti-social, and narcissistic personality disorder, and between fearful-avoidant attachment and avoidant and borderline personality disorder (For reviews, see: Westen, Nakash, Thomas, \& Bradley, 2006; Mikulincer \& Shaver, 2007, Chapter 13; Levy, Johnson, Clouthier, Scala, \& Temes, 2015).

\section{Introjective and anaclitic psychopathology in SCM self- narratives}

Hermans and Hermans-Jansen (1995) used a mix of personality disorders and depressive disorders to describe the dysfunctional qualities of one-sided self-narratives. Their de- scriptions of 'cases' clearly illustrate the (theoretical) similarities between overdependency $(+\mathrm{O})$ and dependent personality, between limitlessness $(+\mathrm{HH})$ and histrionic personality, between grandiosity $(+\mathrm{S})$ and narcissistic personality, and between other-directed hostility $(-\mathrm{S})$ and antisocial personality (For a discussion, see Van Geel, 2000; see also Table 2). Regarding depression, Hermans and Hermans-Jansen distinguished three types. The prolonged grieving depression $(-\mathrm{O})$ is conceptually comparable with anaclitic/dependency depression, as they both involve an intense (but frustrated) longing for contact with others. Nietzel and Harris (1990) speculated that "sociotropes chase after their interpersonal losses longer and more intensely" ( $p$. 292), which brings Beck's concept of sociotropy close to the thematic content of $-\mathrm{O}$ or Fugit Amor narratives: the futile attempt to reach the other. In addition, Blatt's Dependency scale and Beck's Sociotropy scale are consistently connected to the Big Five scales of Neuroticism and Agreeableness (Zuroff, 1994; Dunkley, Blankstein \& Flett, 1997). This provides empirical evidence for the notion that sociotropy or dependency subsumes a neurotic $(\mathrm{N}>\mathrm{P})$ and an agreeable component $(\mathrm{O}>\mathrm{S})$, both present in the $-\mathrm{O}$ experience. The depression with self-directed hostility $(-\mathrm{S})$ is conceptually comparable with introjective/self-critical depression, as they both involve an intensified (but frustrated) need for self-enhancement and relentless self-criticism. Hermans and Hermans-Jansen (1995) speak of a helplessness or hopelessness depression when people have a preponderance of -LL types represented in their self-narrative. This deeper level of depression is often accompanied by valuations referring to an overall downhearted state of mind (e.g., "The threat that hangs over the whole world: Any number of things can happen, and you can't do anything”, p. 171) or persistent apathy (e.g., "I feel hopeless and have no outlook", p. 171). Evidently, from a treatment point of view, this type of depression is most acute. To conclude, as hermeneutics is the art of interpreting texts, the writings of Hermans and Hermans-Jansen (1995) have contributed to the interpretative hermeneutic validity of the Self-Confrontation Method. However, (classical construct) validity studies (with larger groups) in which theoretical views about psychopathology are being challenged and scrutinized, are rather sparse.

Based on empirical research and theoretical considerations, Van Geel (2000) heuristically assembled the dysfunctions as described by Hermans and Hermans-Jansen (1995), together with several personality disorders and depressive personality scales against the background of eight subscales from interpersonal theory. This supported the presumed relationships between Hermans' (theoretical) constructs and the anaclitic and introjective personality dimensions. In a (classical) validity study of the SCM-typology, Van Geel (2000) calculated correlations between frequencies of the six types of valuations (in a person's SCM self-narrative) and several introjective and anaclitic personality scales in a group of university students $(N=67)$. He found moderate positive correlations between the percentage of $-\mathrm{S}$ valuations and Complacency (i.e., having little concern for other people and their problems) and Criticism (i.e., the tendency to be distrustful and hostile). The percentage of $-\mathrm{O}$ valuations correlated positively with Sensitivity to Others (i.e., 
being preoccupied with the judgment and wishes of others, and having a high need for closeness and affection). Obviously, more research is needed to investigate the theoretical claims made by Hermans and Hermans-Jansen (1995).

\section{The present studies}

We present three related studies, which are based on the same data extracted from SCM self-investigations with one hundred persons. The SCM was applied as originally intended for use in clinical practice. Hence, we employed the original set of questions and allowed persons full freedom in constructing as many valuations as they would like to come up with (see Method Section).

Initially, we focussed on the so-called General Feeling, the standard valuation providing a summary of the S-O-P-N feelings that dominate a person's life at the time of the selfinvestigation. The four aspects of the General Feeling were correlated with the anaclitic and introjective personality measures (cf. AAC model, discussed previously). Because attachment anxiety shares a conceptual similarity with the theme of unfulfilled longing — viz. they both concern a submissive-communal interpersonal orientation - one would expect the anxiety subscales to correlate positively with the $\mathrm{O}$ and $\mathrm{N}$ scales (cf. -O type). Conceptually, attachment avoidance and the need for control both share a similarity with the theme of anger and opposition, in that they represent a cold-disconnected interpersonal orientation. Therefore, we expected these personality measures to correlate positively with the $\mathrm{S}$ and $\mathrm{N}$ scales (cf. $-\mathrm{S}$ type). A concept mapping technique, the so-called 'hexagon analysis', was employed to investigate these kinds of relationships graphically. The goal of this study was to obtain a first impression of the anaclitic and introjective features of the SCM typology.

The second study is also quantitative in nature, but here the focus was on the 'frequency' of each of the six types of valuations. In this way, the prominence of each of the themes in the SCM self-narrative could be ascertained. For example, the number of $-\mathrm{O}$ valuations gives an indication as to how prominent the theme of 'unfulfilled longing' is in a person's self-narrative. These aggregated SCM measures were also correlated with the subscales of the AAC model. Theoretically, depression with self-directed hostility (characterized by many $-\mathrm{S}$ valuations) is linked to introjective psychopathology (i.e., attachment avoidance and control), while prolonged grieving depression (characterized by many $-\mathrm{O}$ valuations) resembles anaclitic psychopathology (i.e., attachment anxiety). In the light of validation, one would expect that hopelessness and helplessness depression (characterized by many - LL valuations) is linked to the anaclitic personality dimensions (i.e., subscales of attachment anxiety) as well as the introjective personality dimensions (i.e., avoidance of intimacy; lack of trust; need for control). The objective of this study was to investigate what kind of features in an SCM self-narrative may signal anaclitic and introjective interpersonal problems. It should be noted that this second study is more fundamental than the first one, as all valuations of a person's self-narrative are taken into account.
The third study is principally qualitative in nature, as we examined the content of valuations, i.e., the sentences persons have formulated. The primary objective was to examine the narratives articulated by 'insecurely attached persons', i.e., classified as either preoccupied, dismissiveavoidant, or fearful-avoidant. For that purpose, initially, cluster analysis was applied (using the six self-report AAC subscales), with which persons were allocated to one of four attachment prototypes. Subsequently, within each of the insecure attachment clusters we explored the nature of $-\mathrm{O},-\mathrm{S}$ and -LL valuations, expecting to discover meaningful differences. By adopting such a interpretative hermeneutic approach, we were also expecting to discover new themes associated with anaclitic and introjective psychopathology.

\section{METHOD}

\section{Subjects and procedure}

The data were collected in 2008 by five psychology students who did their master research under supervision of the first and second author of this article. Participants were recruited from the student population of the Netherlands Open University by sending an e-mail to 2,167 students from different faculties. This e-mail contained an invitation to participate in a study about 'intimate relationships' with the aid of the Self-Confrontation Method. A medical ethical committee (METiGG) approved the study and informed consent was needed from participants. Eighty-five subjects who received the invitation agreed to participate in the study. Fifteen additional subjects were recruited from among the circle of friends and relatives of the five psychology students. People with mental health or psychiatric problems were excluded from participation because of the expected mental load and any associated risks (guidelines METiGG). One hundred respondents were thus included (36 men, 64 women; mean age $=43.4$ years; $S D=9.9 ;$ min- $\max =20-67)$. There was no significant age difference between women and men (43.9 versus 42.7).

\section{SCM self-investigations}

The self-investigations of each participant consisted of a thorough conversation with one of five trainees, and was based on an extended set of questions and procedures outlined by Hermans (1981, pp. 15-17) and Hermans and Hermans-Jansen (1995, pp. 275-276). A person performing a self-investigation with the SCM is invited to construct 'valuations' (i.e., dynamic elements that reflect important experiences) in an intensive dialogue with a psychologist. Syntactically, the sentence is considered the most efficient unit to encompass a personal experience in its full richness. Ideally, a valuation is a sentence about a personal subject, elaborated in detail and containing a time-space element. Valuations are typically elicited with the aid of a set of different stimuli varying from questions about 'main activities', 'what a person enjoys doing', 'often thinks about' to elicitors about 'people that arouse antagonistic feelings' or 'people with whom one feels closely allied' (Hermans \& Her- 
mans-Jansen, 1995). As an example, in reaction to the elicitor "Is there someone who is important in your life and to whom you feel closely allied?" a person may start talking about his or her family and eventually formulate the valuation: "Due to our preoccupation with our sick daughter, our son was rather neglected" (Hermans \& Hermans-Jansen, 1995, p.89). Notice that this sentence has a specific subject (neglect of a son), a delineated period (of sickness), and an implied motivation (to improve the contact with the son). Sentences of this kind gradually emerge during the dialogue. These investigations, which lasted three hours on average, resulted in the formulation of a number of valuations (typically between 20 and 50), covering the person's concerns about their past, present, and future.

After the conversation the trainee prepared an Excel-file, in which all valuations of a person were entered in separate spreadsheets. The last two spreadsheets contained two standard valuations concerning General Feeling ('How do you generally feel lately?') and Ideal Feeling ('How would you ideally like to feel?'). This personalized Excel-file was sent to the participant via e-mail. The following list of affects was visible on each spreadsheet: Joy (1), powerlessness (2), self-esteem (3), anxiety (4), happiness (5), worry (6), strength (7), stress (8), enjoyment (9), caring (10), love (11), self-alienation (12), unhappiness (13), tenderness (14), guilt (15), solidarity (16), self-confidence (17), loneliness (18), warmth (19), trust (20), inferiority (21), intimacy (22), safety (23), anger (24), despondency (25), pride (26), energy (27), disappointment (28), inner calm (29), freedom (30). Participants were instructed to read each valuation, and to indicate to what extent the particular affects were associated with that specific valuation. For this purpose, a 6-point scale was used, with the following conventions: $0=$ not at all (experienced in this valuation) or not applicable, $1=$ slightly, $2=$ to some extent, $3=$ rather much, $4=$ much, and 5=very much. In this way, each valuation received an affect profile, or valuation type, within the context of the valuation system as a whole.

About two weeks after the self-investigation, a session took place in which the valuation system was discussed. This involved a session of 1-2 hours, in which, amongst others, a hierarchy of mean affect scores was discussed and similarities between valuations were studied, aided by a visual representation of the whole valuation system. Valuations were projected in an affect space so that clusters of similar valuations (sharing a common emotional-motivational theme) could easily be discerned (Van Geel \& De Mey, 2004).

\section{SCM-based measures: General feeling and number of each valuation type}

Two categories of measures were derived from each SCMmatrix, by using the affect profiles of the person's valuations, each containing the scores on 30 affect terms. For each affect profile, four scales were created: Self (S), Other (O), Positive (P), and Negative (N) (see the 30-list of Van Geel \& De Mey, 2003, see Appendix; Hermans, HermansJansen \& Van Gilst, 1985). (1) The levels of the S, O, P, and $\mathrm{N}$ scales, as related to the standard valuation 'General Feel- ing', was used for obtaining an impression of feelings dominating a person's life at the time of the self-investigation. Cronbach's alfas for these S, O, P, and N scales were adequate $(.90, .93, .90$ and .92 , respectively). (2) By combining levels of the $\mathrm{S}-\mathrm{O}-\mathrm{P}-\mathrm{N}$ scales each valuation was classified into a typology, and for each SCM-grid the percentages of types of valuations were calculated. Usually, a disjunctive classification method is being used, in which the differences between the $\mathrm{S}$ and $\mathrm{O}$ scale, on the one hand, and between the $\mathrm{P}$ and $\mathrm{N}$ scale, on the other hand, are important criteria (Hermans \& Hermans Jansen, 1995). However, we used a conjunctive classification method, in which the complete profile of $\mathrm{S}-\mathrm{O}-\mathrm{P}-\mathrm{N}$ scores is taken into account (Finn Tschudi, 1995, personal communication). For clarity, the complete SPSS syntax is given in Appendix A. With this method, 2,558 valuations, that is $85.4 \%$ of the total of 2,994 valuations, could be classified into one of the following six types: +HH (1,105), +S (578), +O (130), -S (177), -O (134), and $-\mathrm{LL}$ (434). An additional discriminant analyses of these 2,558 profiles showed that by using the $\mathrm{S}-\mathrm{O}-\mathrm{P}-\mathrm{N}$ scores as predictors of the six-category variable, $96 \%$ was correctly classified, which supports the utility of the conjunctive classification method.

\section{Questionnaire-based measures}

In addition to the SCM self-investigation, every participant filled out a questionnaire about adult attachment (ASQ), and depressive personality factors (PSI). These questionnaires were included in the Excel file to be completed at home and returned by mail. However, instead of the original scales of these instruments we used the scales developed by Van Geel et al. (2016).

The original 24-item Attachment Style Questionnaire (ASQ; Van Oudenhoven \& Hofstra, 2005) was developed to assess Bartholomew's (1990) prototypical attachment styles 'dimensionally'. It consists of four attachment subscales: Secure, Preoccupied, Dismissing-avoidant, Fearfully-avoidant. In this study we used the original Dutch version; for an English translation, see Hofstra et al. (2005). The items had a five-point answer scale from strongly disagree to strongly agree. The original 48-item Personal Style Inventory (PSI; Robins et al., 1994) contains two threefold factors: Sociotropy (Concern about what Others Think, Dependency, and Pleasing Others); and Autonomy (Defensive Separation, Need for Control, and Perfectionism/Self-Criticism). We used a Flemish-Dutch version of the PSI (Luyten, Soenens, Vansteenkiste, \& Corveleyn, 2003). The items had a six-point answer scale from totally disagree to totally agree. In the present study, we discarded the four items about Perfectionism/Self-Criticism (see Bagby et al., 1998; Desmet et al., 2010).

Van Geel et al. (2016) examined the correlational structure of a combined set of ASQ and PSI items in two nonclinical samples $(N=661, N=528)$. Exploratory and confirmatory factor analysis revealed six meaningful factors covering three higher-order factors: attachment anxiety, attachment avoidance, and need for control (See introduction). The attachment anxiety domain comprised three subscales: Concern about what Others Think (8 items, e.g., "I 
Table 3. Zero-order correlations between AAC-scales and aspects of 'General Feeling'

\begin{tabular}{|c|c|c|c|c|}
\hline$\overline{\text { Scales of AAC model }}$ & $\mathrm{S}$ & $\mathrm{O}$ & $\mathrm{P}$ & $\mathrm{N}$ \\
\hline ANXIETY & $-.39^{* *}$ & -.10 & $-.23^{*}$ & $.44^{* *}$ \\
\hline Concern & $-.42^{* *}$ & -.14 & $-.23^{*}$ & $.46^{* *}$ \\
\hline Pleasing & $-.36^{* *}$ & -.07 & -.19 & $.41^{* *}$ \\
\hline Dependency & -.10 & .00 & -.13 & .12 \\
\hline AVOIDANCE-DISTRUST & $-.37^{* *}$ & $-.39^{* *}$ & $-.39^{* * *}$ & $.41^{* * *}$ \\
\hline Avoidance & $-.41^{* *}$ & $-.37^{* *}$ & $-.40^{* *}$ & $.34^{* *}$ \\
\hline Distrust & $-.23^{*}$ & $-.34^{* *}$ & $-.29^{* *}$ & $.41^{* *}$ \\
\hline CONTROL & -.10 & -.13 & $-.23^{*}$ & $.31^{* *}$ \\
\hline
\end{tabular}

Note: $* p \leq .05, * * p \leq .01, * * * p \leq .001$ (two-tailed). Correlations involving the higher-order AAC scales are in bold face.

am very concerned with how people react to me", in this sample $\alpha=.87, N=100$ ); Pleasing Others ( 8 items, e.g., "I am very sensitive to the effects I have on the feelings of other people", $\alpha=.77)$; and Dependency/difficulty with being alone ( 4 items, e.g., "I find it difficult if I have to be alone all day", $\alpha=.69)$. The attachment avoidance domain included two subscales: Avoidance of Intimacy ( 9 items, e.g., "It is hard for me to open up and talk about my feelings and other personal things", $\alpha=.80$ ); and Distrust (5 items, e.g., "I would like to be open to others, but I feel I can't trust other people", $\alpha=.77)$. The third higher-order factor was a separate scale about Need for Control and Independence $(8$ items, e.g., "I resent it when people try to direct my behavior or activities", $\alpha=.76$ ). A second-order principal components analysis (PCA, Promax) of the subscales confirmed that there were two distinct (correlated) components present in this dataset (explaining $68.4 \%$ of the variance): one component consisted of the three anxiety subscales (loadings > $.70)$ and the other consisted of the other AAC scales (loadings > .54); All secondary loadings were rather small (< $.31)$. In this study we used the higher-order as well as the lower-order scales of the short version of this AnxietyAvoidance-Control model (Van Geel et al., 2016).

\section{Analysis}

In the first study we used correlational and multiple regression analysis. We also employed a concept mapping technique, with which the personality scales were being projected within the boundaries of a hexagonal frame representing the six valuation types, i.e., the most extreme elements (Van Geel \& De Mey, 2004). In the second study, besides correlational analysis, we employed canonical correlational techniques (SPSS CANCORR macro). In addition, we subdivided the dataset into four attachment clusters with the aid of cluster analysis and examined mean differences in percentages of $+\mathrm{HH},+\mathrm{S},+\mathrm{O},-\mathrm{S},-\mathrm{O}$ and $-\mathrm{LL}$ with MANOVA. In the qualitative Study 3, we selected five persons from each of the three 'insecure' attachment clusters, endeavoring to find thematically meaningful self-narratives for further study. We meticulously screened the content of the $-\mathrm{S}$, $-\mathrm{O}$ and $-\mathrm{LL}$ valuations of all insecurely attached persons, searching for texts disclosing anaclitic and introjective themes in past and present. As a heuristic guideline for selection, we were particularly keen on texts about childhood experiences, parental upbringing, attachment and intimacy (in friendship and love relationships). While reading the valuations, we were also attentive to interpersonal and emotional problems and depressed states. In so doing, we eventually selected fifteen persons who were genuinely reflecting on their life experiences in depth during their SCM selfinvestigation. To facilitate interpretation of the texts, every valuation was labelled with a concise description of the main topic.

\section{RESULTS}

\section{General Feeling}

In order to obtain a first impression of the anaclitic and introjective features of the SCM typology, we examined the relationships between the AAC personality measures and the S-O-P-N aspects of the General Feeling. The correlations in Table 3 show that the higher-order Anxiety scale was significantly related to scales referring to Self $(r=-.39)$, Positive (-.23), and Negative affect (.44). Overall, the patterns of correlations were similar for the subscales Concern and Pleasing, but not for Dependency. The latter scale did not display substantial correlations with the SCM affect scales. The higher-order avoidance-distrust scale was significantly related to all SCM scales: Self (-.37), Other (-.39), Positive (-.39), and Negative (.41). This pattern of correlations was also found for both subscales Avoidance and Distrust. The Control scale was only significantly related to Positive affect (-.23) and Negative affect (.31).

We further examined these associations employing multiple regression analysis (MRA), inserting the Self, Other, and Negative scales as predictors of the three 'higher-order' AAC scales. The Positive affect scale was excluded as a predictor because it correlated too high with the Self and Other scales (.81 \& .80, respectively); After removing the Positive affect scale, the average Variance Inflation Index (VIF) dropped from 3.25 (indicating problematic multicollinearity) to a more acceptable level of 1.57 (Field, 2018). The results of the first MRA indicated that the three predictors explained $25.5 \%$ of the variance in higher-order anxiety, $F(3,96)=11.04, p<.0001 ;$ Self $(\beta=-.35, \mathrm{p}<.01)$ and Negative affect $(\beta=.31, \mathrm{p}<.01)$ emerged as significant predictors. The second MRA showed that the same predictors explained $25.8 \%$ of the variance in higher-order avoidance, $F(3,96)=11.15, p<.0001$; here Other $(\beta=-.28, \mathrm{p}<.05)$ 


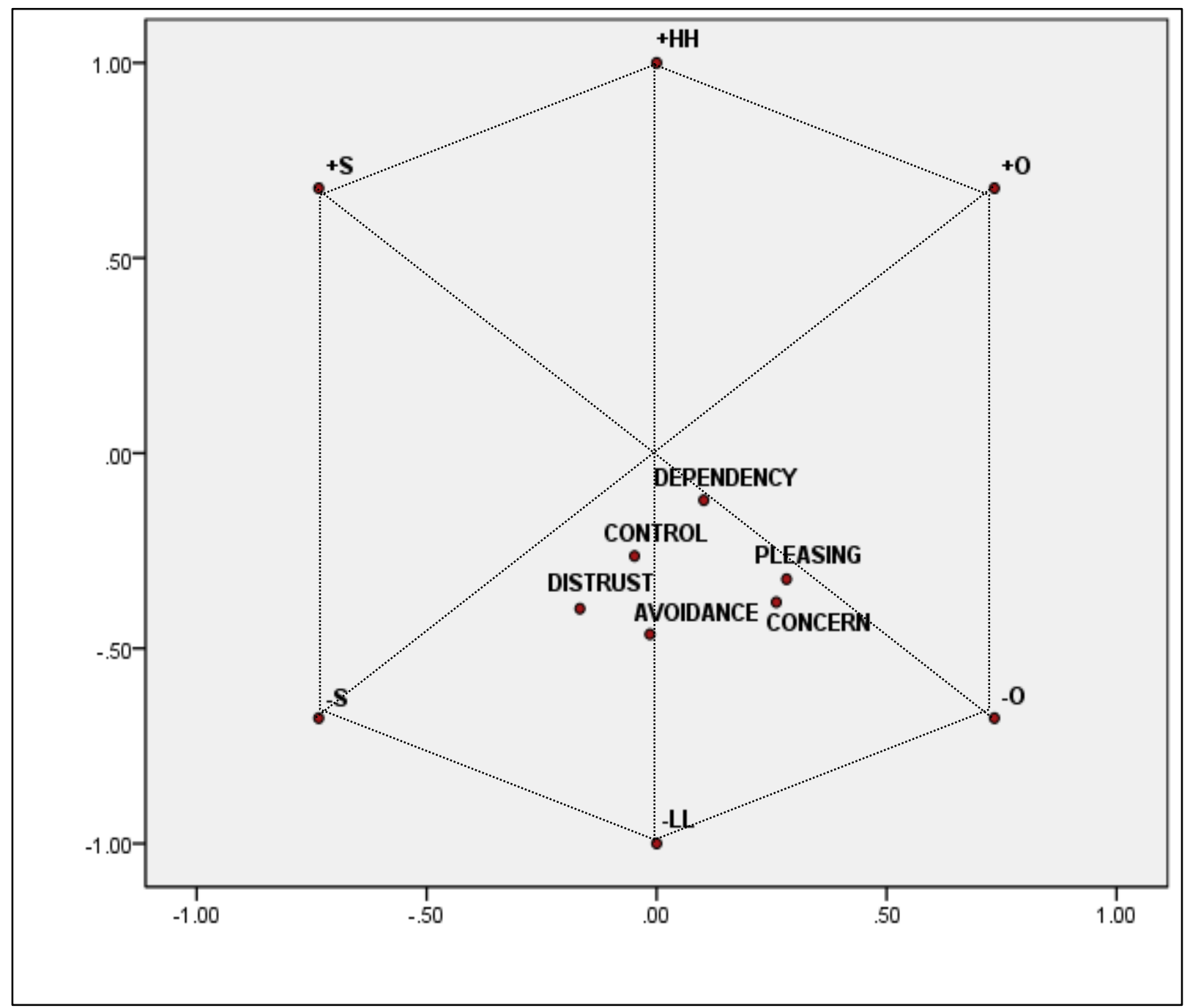

Figure 1. Hexagonal model of SCM typology containing the subscales from the AAC model. $+\mathrm{O}=$ love and unity, $+\mathrm{HH}=$ strength \& unity, $+\mathrm{S}=$ succes \& autonomy, $-\mathrm{S}=$ anger \& opposition, $-\mathrm{LL}=$ powerlessness \& isolation, $-\mathrm{O}=$ unfulfilled longing \& loss.

and Negative affect $(\beta=.31, \mathrm{p}<.01)$ were significant predictors. The third MRA showed that the same three predictors explained $11.0 \%$ of the variance in Control, $F(3,96)=$ $3.96, p<.05$, but only Negative affect $(\beta=.35, \mathrm{p}<.01)$ was significant.

For a graphical integration of the variables, a so-called 'external hexagon analysis' was applied (Van Geel, 2011). This kind of concept mapping provides a picture of the AAC scales against a hexagonal 'two-dimensional' background of SCM prototypes. Technically, scales are being projected into the hexagon by calculating the correlations with the two underlying main axis, i.e., 'Self vs. Other' (Dimension 1), and 'Negative vs. Positive' (Dimension 2). The technique is fairly straightforward as it uses the factor score coefficients derived from a principal component analysis of S-O-P-N scales of the extreme prototypes (Van Geel \& De Mey, 2004). Usually, the following formulas are being used in the calculations:

COMPUTE DIM1 $=(\mathrm{O}-\mathrm{S})$

COMPUTE DIM $2=0.38269 *(\mathrm{O}+\mathrm{S})+0.92388 *(\mathrm{P}-\mathrm{N})-1.91343$.
Figure 1 presents the result of this (fixed) hexagon analysis. The projection shows how the six personality scales are interrelated affectively and thematically, i.e., in terms of their shared similarity with the SCM prototypes. For a correct understanding: the projection shows how all of the variables are interrelated. So, variables that are close together in the hexagon will more often than not inter-correlate positively, but the projection may deform those relations. The positioning of the three anxiety subscales on the bottom right of the hexagon signifies that they are associated with 'unfulfilled longing and loss' $(-\mathrm{O})$. However, Dependency is close to the origin which denotes that the affective content of this variable is not great. The depiction further shows that Avoidance and Control, located in the lower part of the depiction, are associated with 'powerlessness and isolation' (LL). Finally, Distrust has more in common with the theme of 'anger and opposition' $(-S)$. Overall, it seems that there are two appreciable clusters. 
Table 4. Zero-order correlations between AAC-scales and percentages of SCM-types

\begin{tabular}{|c|c|c|c|c|c|c|}
\hline \multirow{2}{*}{ Scales of AAC model } & \multicolumn{6}{|c|}{ Percentages of SCM types } \\
\hline & $+\mathrm{HH}$ & $+\mathrm{S}$ & $+\mathrm{O}$ & $-\mathrm{S}$ & $-\mathrm{O}$ & $-\mathrm{LL}$ \\
\hline ANXIETY & $-.25^{*}$ & $-.20^{*}$ & .08 & -.05 & $.21^{*}$ & $.42^{* * *}$ \\
\hline Concern & $-.27^{* *}$ & -.10 & .06 & -.12 & .11 & $.48^{* *}$ \\
\hline Pleasing & $-.23^{*}$ & $-.20^{*}$ & .13 & -.05 & $.24^{*}$ & $.34^{* *}$ \\
\hline Dependency & -.04 & $-.27^{* *}$ & -.03 & .11 & .19 & .13 \\
\hline AVOIDANCE-DISTRUST & $-.34^{* *}$ & .15 & .05 & .04 & -.14 & $.38^{* * *}$ \\
\hline Avoidance & $-.30^{* *}$ & .13 & .11 & -.04 & -.12 & $.33^{* *}$ \\
\hline Distrust & $-.33^{* *}$ & .15 & -.06 & .17 & -.14 & $.37^{* *}$ \\
\hline CONTROL & -.18 & -.03 & -.13 & $.21^{*}$ & .06 & $.34^{* *}$ \\
\hline
\end{tabular}

Note: $* p \leq .05, * * p \leq .01, * * * p \leq .001$ (two-tailed). Correlations involving the higher-order AAC scales are in bold face.

\section{Frequencies of SCM types}

In order to obtain a more profound impression of the anaclitic and introjective features of the SCM typology, the AAC personality measures were correlated with the percentages of valuation types (extracted from each SCM grid). Table 4 shows that the higher-order Anxiety scale was significantly related to the percentages of $+\mathrm{HH}(-.25),+\mathrm{S}(-.20)$, $-\mathrm{O}(.21)$ and -LL (.42), a comparable pattern of correlations was observed for the subscale Pleasing: $+\mathrm{HH}(-.23),+\mathrm{S}$ $(-.20),-\mathrm{O}(.24)$ and $-\mathrm{LL}(.34)$. Concern only correlated with the percentages of $+\mathrm{HH}(-.27)$ and $-\mathrm{LL}(.48)$, Dependency only with $+\mathrm{S}(-.27)$. The higher-order avoidance-distrust scale was substantially related to $+\mathrm{HH}$ (-.34), and -LL (.38), a pattern which was also found for the subscales Avoidance and Distrust. Control displayed significant correlations with $-\mathrm{S}(.21)$ and -LL (.34).

In order to obtain a multivariate perspective on the relationships between the six SCM types and six AAC subscales, we performed a canonical correlation analysis. With this technique so-called canonical variates are being extracted from two sets of variables, maximizing shared variance. "The goal is to redistribute the variance of the original variables into a few pairs of canonical variates, each pair capturing a large share of variance and defined by linear combinations of $(\ldots)$ variables on one side and (...) variables on the other. Linear combinations are chosen to maximize the canonical correlation for each pair of canonical variates" (Tabachnick \& Fidell, 2001, p. 183). The results showed that it was possible to extract three significant variates from the data. The first canonical correlation was .57 (33.0\% of the variance), the second was .47 (22.4\%), and the third was $.46(21.4 \%)$. The three canonical correlations were in combination statistically significant, Wilks $\Lambda=.38, F(36,389)=$ $2.63, p<.0001$. After removing the first canonical correlation, the second and third canonical correlations were still significant, Wilks $\Lambda=.57, F(25,332)=2.15, p<.01$. The third canonical correlation alone was also significant, Wilks $\Lambda=.74, F(16,275)=1.80, p<.05$. The results are depicted in Table 5 .

The canonical structure (see columns $R$ in Table 5) reveals that every variate was predominantly uniquely connected to one of the negative SCM types contrasting with its theoretical opposite: "+HH vs. -LL", "+S vs. $-\mathrm{O}$ " and "+O vs. $-\mathrm{S}$ ". The first variate showed that a low percentage of $+\mathrm{HH}$ types and a high percentage of -LL types were associated with high scores on all AAC subscales (especially Concern, Pleasing, Avoidance, Distrust, and Control), suggesting that a sense of 'powerlessness and isolation' is associated with 'general attachment insecurity' (cf. fearfulavoidant attachment). The second variate showed that a low percentage of $+\mathrm{S}$ and a high percentage of $-\mathrm{O}$ types were related to higher Pleasing and Dependency and lower Avoidance and Distrust, suggesting that a sense of 'unfulfilled longing and loss' $(-\mathrm{O})$ is associated with distinct anaclitic features (cf. preoccupied attachment). Finally, the third variate showed that a low percentage of $+\mathrm{O}$ and a high percentage of $-\mathrm{S}$ types were associated with high scores on Distrust and Control, suggesting that 'anger and opposition' is associated with the need for control/independence (cf. dismissive-avoidant attachment). The redundancies disclose that the first SCM variate accounts for $15 \%$ of the variance in the AAC variables, the second SCM variate explains 3\% and the third $2 \%$. So, together, the three SCM variates explain $20 \%$ of the variance in AAC variables. Conversely, the three AAC variates explain $15 \%$ of the variance in SCM variables.

\section{Four attachment clusters}

We subdivided the dataset into four clusters (representing the four attachment prototypes) by applying cluster analysis. Several 'hierarchical' cluster algorithms were used (on the standardized scores of six scales from the AAC model), but the most promising and comprehensible results were obtained with Ward's method (i.e., with squared Euclidean distances). To ascertain the stability of the solution an additional 'nonhierarchical' clustering was performed with the centroids from the hierarchical procedure as seeds. The agreement measure between these two four-cluster solutions indicated substantial convergence $($ Карра $=.86)$. The results from the nonhierarchical four-cluster solution with a given start configuration were used in this study. A geometric representation (obtained via principal components analysis) supported the choice for a division into four clusters, as clusters were rather well separated from each other in just two dimensions. 
Table 5. Results of the canonical correlation analysis of the association between the percentages SCM types and lower-order scales of the Anxiety-Avoidance-Control model

\begin{tabular}{|c|c|c|c|c|c|c|}
\hline \multirow{3}{*}{ SCM TYPES } & \multicolumn{2}{|c|}{ First Variate } & \multicolumn{2}{|c|}{ Second Variate } & \multicolumn{2}{|c|}{ Third Variate } \\
\hline & $\mathrm{R}$ & $\mathrm{SC}$ & $\mathrm{R}$ & $\mathrm{SC}$ & $\mathrm{R}$ & SC \\
\hline & & & & & & \\
\hline$+\mathrm{HH}$ & -.53 & -.74 & -.32 & .48 & .11 & -.45 \\
\hline$+\mathrm{S}$ & -.12 & -.41 & .78 & .89 & .18 & -.13 \\
\hline$+\mathrm{O}$ & -.09 & -.52 & -.07 & .23 & -.55 & -.58 \\
\hline$-\mathrm{S}$ & .15 & .06 & -.15 & -.08 & .85 & .69 \\
\hline$-\mathrm{O}$ & .15 & .15 & -.72 & -.42 & -.26 & -.22 \\
\hline \multirow[t]{6}{*}{$-\mathrm{LL}$} & .88 & .55 & .31 & .52 & -.26 & -.44 \\
\hline & \multicolumn{6}{|c|}{ Proportions of extracted variance } \\
\hline & .19 & & .23 & & .20 & \\
\hline & \multicolumn{6}{|c|}{ Redundancies } \\
\hline & .06 & & .05 & & .04 & \\
\hline & $\mathrm{R}$ & $\mathrm{SC}$ & $\mathrm{R}$ & $\mathrm{SC}$ & $\mathrm{R}$ & $\mathrm{SC}$ \\
\hline \multicolumn{7}{|l|}{ AAC SCALES } \\
\hline Concern & .84 & .52 & .00 & .59 & -.46 & -.76 \\
\hline Pleasing & .71 & .09 & -.38 & -.79 & -.39 & -.26 \\
\hline Dependency & .45 & .06 & -.60 & -.66 & .11 & .35 \\
\hline Avoidance & .47 & -.14 & .48 & .32 & -.20 & -.52 \\
\hline Distrust & .70 & .34 & .42 & .34 & .32 & .87 \\
\hline \multirow[t]{5}{*}{ Control } & .74 & .42 & -.02 & -.03 & .31 & .40 \\
\hline & \multicolumn{6}{|c|}{ Proportions of extracted variance } \\
\hline & .45 & & .15 & & .10 & \\
\hline & \multicolumn{6}{|c|}{ Redundancies } \\
\hline & \multicolumn{4}{|c|}{.03} & \multicolumn{2}{|l|}{.02} \\
\hline Canonical Correlation & \multicolumn{2}{|l|}{.57} & .47 & \multicolumn{3}{|c|}{.46} \\
\hline \multicolumn{7}{|c|}{$\begin{array}{l}\text { Note: } R=\text { correlation between individual variables and canonical variable; absolute loadings }>.30 \text { are in boldface. } S C=\text { Standardized Canonical } \\
\text { Coefficients; These SC's are used to calculate the loadings, but are typically not used for the interpretation of the variates. The proportion of extracted } \\
\text { variance refers to the amount of variance that a variate shares with one of the (two) sets of variables. It is the sum of the squared loadings divided by the } \\
\text { number of variables in a set (Tabachnick \& Fidell, 2001). The redundancy index measures to what degree one set of variables can be reconstructed on } \\
\text { the basis of knowledge of the other set of variables (Tacq, 1997). It is obtained by multiplying the proportion of extracted variance with the squared } \\
\text { canonical correlation (Tabachnick \& Fidell, 2001). }\end{array}$} \\
\hline
\end{tabular}

Table 6 summarizes the means of the four clusters on the six AAC scales. The profiles of mean scores of these clusters are as would be for the four attachment prototypes. Persons allocated to the first cluster represent a secure group: they display below average scores on all scales. The second cluster can be described as a preoccupied cluster, these persons display above average scores on the three anaclitic subscales, especially on dependency. The third cluster represents a dismissing-avoidant cluster, with high averages on the three introjective scales. The fourth cluster is clearly a fearful-avoidant cluster, as it displays above average scores on all subscales, in particular on concern, pleasing, avoidance and distrust. Although the effect sizes $\left(\eta^{2}\right)$ indicate that all six sales contribute to the differentiation between clusters, the largest differences are related to differences in Concern $\left(\eta^{2}=.65\right)$ and Distrust $\left(\eta^{2}=.58\right)$. We conclude that four meaningful clusters have been extracted from the data.
Table 7 depicts the mean proportions of SCM types as extracted from the SCM self-investigations for the four attachment clusters. MANOVA revealed significant multivariate differences, Roy's $\Theta=.65, F(6,93)=9.99, p<.001$. Univariate ANOVAs exposed substantial differences in the average proportions of -LL $\left(\eta^{2}=.37\right)$, moderate differences in $+\mathrm{HH}\left(\eta^{2}=.16\right)$ and $-\mathrm{O}\left(\eta^{2}=.15\right)$, and small differences in $+S\left(\eta^{2}=.09\right)$ and $-S\left(\eta^{2}=.06\right)$. Contrast analysis revealed that the fearful-avoidant group formulated conspicuously less $+\mathrm{HH}$ types than the other three groups combined, $\Psi=-$ $.20, t(96)=3.91, p<.001$, and far more -LL types than the other three groups, $\Psi=.20, t(96)=7.00, p<.001$. The preoccupied group displayed a higher average proportion of O types as compared to the other three combined groups, $\Psi=.07, t(96)=4.07, p<.001$. Regarding the proportions of $-\mathrm{S}$, there was a small difference between the dismissiveavoidant and the other groups, $\Psi=.04, t(96)=2.30, p<.05$. 
Table 6. Means of clusters for the four-cluster solution $(N=100)$

\begin{tabular}{lcccccc}
\hline Subscales $^{\mathrm{a}}$ & $\begin{array}{c}\text { Cluster 1 } \\
\text { Secure }\end{array}$ & $\begin{array}{c}\text { Cluster 2 } \\
\text { Preoccupied }\end{array}$ & $\begin{array}{c}\text { Cluster 3 } \\
\text { Dismissing-avoidant }\end{array}$ & $\begin{array}{c}\text { Cluster } 4 \\
\text { Fearful-avoidant }\end{array}$ & $F(3,96)$ & $\eta^{2}$ \\
\hline Concern & & & & & & \\
Pleasing & $-.56^{\mathrm{a}}$ & $.79^{\mathrm{b}}$ & $-.28^{\mathrm{a}}$ & $1.56^{\mathrm{c}}$ & $59.71^{* * *}$ & .65 \\
Dependency & $-.57^{\mathrm{a}}$ & $1.00^{\mathrm{b}}$ & $-.02^{\mathrm{a}}$ & $1.10^{\mathrm{b}}$ & $30.40^{* * *}$ & .49 \\
Avoidance & $-.34^{\mathrm{a}}$ & $1.56^{\mathrm{c}}$ & $-.40^{\mathrm{a}}$ & $.43^{\mathrm{b}}$ & $22.69^{* * *}$ & .41 \\
Distrust & $-.55^{\mathrm{a}}$ & $-.31^{\mathrm{a}}$ & $.68^{\mathrm{b}}$ & $1.09^{\mathrm{b}}$ & $26.97^{* * *}$ & .46 \\
Control & $-.60^{\mathrm{a}}$ & $-.34^{\mathrm{a}}$ & $.64^{\mathrm{b}}$ & $1.35^{\mathrm{b}}$ & $44.47^{* * *}$ & .58 \\
& $-.65^{\mathrm{a}}$ & $.41^{\mathrm{b}}$ & $.83^{\mathrm{b}}$ & $.67^{\mathrm{b}}$ & $26.95^{* * *}$ & .46 \\
\hline Number of cases & & & & & 16 & \\
\hline
\end{tabular}

Note: Means are obtained for standardized variables $(M=0, S D=1)$. Means within each row with different superscripts differ significantly at $p<.05$ (cf. Bonferroni). * $p \leq .05, * * p \leq .01, * * * p \leq .001$.

Table 7. Mean proportions of SCM types for four clusters $(N=100)$

\begin{tabular}{|c|c|c|c|c|c|c|}
\hline & $\begin{array}{l}\text { Secure } \\
(n=51)\end{array}$ & $\begin{array}{l}\text { Preoccupied } \\
(n=12)\end{array}$ & $\begin{array}{c}\text { Dismissive-avoidant } \\
(n=21)\end{array}$ & $\begin{array}{c}\text { Fearful-avoidant } \\
\quad(n=16)\end{array}$ & $F(3.96)$ & $\eta^{2}$ \\
\hline$+\mathrm{HH}$ & $.42^{\mathrm{a}}(.21)$ & $.42^{\mathrm{a}}(.13)$ & $.37^{\mathrm{a}}(.16)$ & $.20^{\mathrm{b}}(.12)$ & $6.24^{\text {*** }}$ & .16 \\
\hline$+\mathrm{S}$ & $.20^{\mathrm{a}}(.13)$ & $.10^{\mathrm{b}}(.09)$ & $.21^{\mathrm{a}}(.12)$ & $.22^{\mathrm{a}}(.08)$ & $3.21^{*}$ & .09 \\
\hline$+\mathrm{O}$ & $.04(.07)$ & $.03(.05)$ & $.04(.07)$ & $.05(.06)$ & .24 & .01 \\
\hline$-\mathrm{S}$ & $.05(.06)$ & $.06(.06)$ & $.09(.09)$ & $.05(.05)$ & 2.13 & .06 \\
\hline$-\mathrm{O}$ & $.04^{\mathrm{a}}(.05)$ & $.10^{b}(.09)$ & $.03^{\mathrm{a}}(.04)$ & $.03^{\mathrm{a}}(.04)$ & $5.56^{* *}$ & .15 \\
\hline$-\mathrm{LL}$ & $.10^{\mathrm{a}}(.09)$ & $.14^{\mathrm{a}}(.10)$ & $.11^{\mathrm{a}}(.08)$ & $.31^{\mathrm{b}}(.13)$ & $19.17^{* * * *}$ & .37 \\
\hline
\end{tabular}

Note: Means with different superscripts differ significantly at $p<.05$ (cf. Bonferroni). SDs are in brackets. * $p \leq .05, * * p \leq .01, * * * p \leq .001$. Characteristic (high or low) proportions are in boldface.

\section{Insecure attachment: introjective and anaclitic themes in SCM texts}

In the previous two studies, we examined the anaclitic and introjective features of the SCM typology, by focusing on the numerical aspect of the SCM self-investigations. Although such a quantitative approach has its merits, it is also limiting as texts remain hidden behind a label or typification. We now turn to the texts of $-\mathrm{S},-\mathrm{O}$ and $-\mathrm{LL}$ valuations of persons who have been classified as 'insecurely attached' according to their scores on the AAC personality scales. Three tables each contain the valuations of five persons who have been allocated to either the preoccupied (Table 8), the dismissive-avoidant (Table 9), or the fearful-avoidant attachment cluster (Table 10).

\section{Preoccupied cluster}

The first preoccupied attached person (Table 8: P1), formulated several $-\mathrm{O}$ valuations, which may be considered typical of this attachment orientation. The texts of these $-\mathrm{O}$ valuations are not only about loss or bereavement $(2,3)$, but also convey (existential) doubts of having children (1) and empathy for his mother when she's being criticized (4). He also reflects (rather casually) about a serious relationship in the past (5), responding with 'powerlessness' (-LL). This feeling of powerlessness ("being a little boy") is also associated with the fear of being rejected by his father (6). The other valuations concern stress at work $(7,-\mathrm{LL})$, annoyance towards clients in general $(8,-\mathrm{S})$ and irritation about the condescending attitude of a specific colleague $(9,-\mathrm{S})$.

The second person (P2) also formulated various $-\mathrm{O}$ valuations. These are, amongst other things, about the 'loss' of (daily) intimacy with her daughter (1) and her difficulty with being alone in the weekend (4). She also expresses her longing for contact with her female friend $(5,-\mathrm{O})$, even when

she is musing upon happier times with her $(6,-\mathrm{O})$. This valuation 6 displays a so-called discrepancy between text ("being glad") and affect $(\mathrm{N}>\mathrm{P})$. She also describes her experiences of a difficult period during which she was altruistically 'nursing' her sick husband $(2,3$ : both $-\mathrm{O})$, and he was threatening to leave her $(7,-\mathrm{LL})$. In her effort to articulate this painful experience - first helping him and subsequently being rejected - she still seems to empathize with him when phrasing his thoughts and considerations (7, 8: both $-\mathrm{LL}$ ). In one valuation she describes how she was able to break up a friendship relationship, thus showing that (sometimes) she is able to stand up for herself $(9,-\mathrm{S})$.

In the self-narrative of the third person (P3), $-\mathrm{O}$ valuations were abundant too, but, at first site, are not so clearly about 'unfulfilled longing or loss'. In the first valuation, she describes the feeling of being excluded when she happened to hear about her father's mental problems (1); a similar theme of exclusion is mentioned when her father was giving a sermon (in church) in which he spoke about his personal worries (4). It seems that in these texts she's not only expressing her concerns for her father, but also a longing for contact $(-\mathrm{O})$. She delineates a period in her life when she 
P1: $+H H=14,+S=10,+O=0,-S=2,-O=4,-L L=5$. Male, age 31 .

1. I have doubts about having children myself because of the concerns that go along with that. I ask myself whether I can provide the nurturing that is needed to let the child grow up without worries (-O: $\left.\begin{array}{llll}1.67 & 3.17 & 2.00 & 3.25\end{array}\right)$.

2. I experience intense sorrow by the loss/death of a pet. I was very sad every time one of our dogs died (-O: $\left.\begin{array}{llll}2.00 & 5.00 & 2.33 & 2.92\end{array}\right)$.

3. During my father's illness, I experienced a lot of fear and sorrow about a future without him. During his illness it became clear to me that he didn't have eternal life and that it was possible that he would die (-O: $1.33 \quad 4.83 \quad .50 \quad 3.58$ )

4. I feel my mother's pain about the statements of my brother about her. The criticism of X about their way of raising him. She keeps silent then, but I know that she is hurt by it $\left(\begin{array}{llll}-\mathrm{O}: & .83 & 3.17 & .00\end{array}\right.$ 3.67).

5. I regret having stayed in this relation for so long. I thought I was ready for a relation and that I had found my "true" love. But the motives were wrong and the foundation of the relationship was not right (-LL: $1.00 \quad .67 \quad .67 \quad 3.83)$.

6. I sometimes feel like a little boy, put in the corner by my father. I don't like to tell him things of which I know that he doesn't really approve of. I regret that very much (-LL: $2.00 \quad 1.67 \quad 2.173 .83$ ).

7. I sometimes feel that clients ask impossible things of me at work. They think I can put everything right. Like I am some kind of miracle doctor who can make any illness go away (-LL: $1.00 \quad .50$ .33 4.17).

8. I find it difficult to see that people don't take responsibility about getting or fixing their illnesses. It is not my problem, but their problem. I want to help them but ultimately they have to do the work themselves (-S: $1.67 \quad .50 \quad .33 \quad 2.50)$.

9. I resent the sometimes condescending behavior of my colleague towards clients. I think it demonstrates little respect for the clients. He doesn't see clients as people, but instead thinks of them as

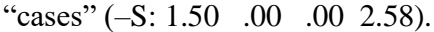

\section{$P 2:+H H=10,+S=0,+O=1,-S=4,-O=6,-L L=8$. Female, age 44.}

1. Now that she is living on her own, I miss my daughter. I still have three men living at home (2 sons and my husband), but I have a different kind of relationship with them than with my daughter. With her I felt more intimacy (-O: $\left.\begin{array}{llll}3.00 & 4.67 & 1.83 & 2.17\end{array}\right)$.

2. During his burn-out period, my husband resembled a psychiatric patient. That was very difficult for me. I didn't recognize him as my husband anymore; almost couldn't have a mentally equivalent contact with him (-O: $\left.\begin{array}{llll}1.50 & 2.83 & .33 & 4.08\end{array}\right)$

3. During his burn-out period, I took care of my husband as if he was a child. It was very difficult and hard for me to treat my husband at that level and also that he allowed me treat him like that. I bathed him in lavender because he loved that (-O: $\left.\begin{array}{llll}1.50 & 2.67 & .67 & 3.83\end{array}\right)$.

4. I often feel lonely during the weekend. If I hear people wishing others a nice weekend, I get sad because I know that I will be lonely in the weekend ( $-\mathrm{O}: \begin{array}{llll}1.67 & 2.50 & 1.17 & 3.33\end{array}$ ).

5. I feel very hurt by the behavior of my ex-female friend. There are times that I don't hear anything from her, because other things are important to her. As a friend, I feel cast aside and that hurts (O: $2.33 \quad 3.00 \quad .33$ 4.08).

6. I am glad to have known my ex-female friend. We had a lot of similarities that were very pleasant. We have been through a lot together. I realize that our friendship brought me a lot of benefits $(-\mathrm{O}$ : $2.17 \quad 3.17 \quad 1.33 \quad 3.08$ ).

7. The discontent of my husband during his burn out period was aimed at his relationship with me. Our relationship didn't give him any satisfaction anymore; he thought he was better off with another

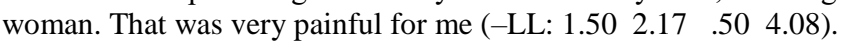

8. It hurts to have to notice that starting a family was a kind of project for my husband. Seen from the viewpoint of his slightly autistic nature, I have the idea that, right now, he feels that his project is finished (-LL $1.83 \quad 2.17 \quad 1.67 \quad 3.17$ ).

9. Before all else, I was angry and determined when I sent the e-mail telling my ex-female friend that I wanted to end our friendship. She had hurt me too many times (-S: $\left.\begin{array}{llll}3.67 & 2.67 & 1.00 & 3.58\end{array}\right)$.

P3: $+H H=14,+S=0,+O=1,-S=0,-O=6,-L L=2$. Female, age 49.

1. I found it very intense to hear my mother tell someone else about my father being overstressed. She didn't tell it to me, but I then realized the seriousness of his stress. How weird my father's behavior has been (-O: $\left.\begin{array}{llll}1.33 & 3.00 & 1.17 & 1.75\end{array}\right)$.

2. It was very intense for me, when my eldest son told me he would soon be a father; he was only 23 years of age, so very young. The pregnancy presented me with many concerns and responsibilities; will this be all right in the end? (-O: $\left.\begin{array}{lllll}1.67 & 3.67 & 1.50 & 2.33\end{array}\right)$.
SELF-CRITICAL

PERFECTIONISM

(ABOUT BEING A PARENT)

LOSS/BEREAVEMENT

FEAR OF

LOSS/BEREAVEMENT

CONCERN FOR

VULNERABLE OTHER

LOSS

FEAR OF BEING REJECTED (BY PARENT)/

PLEASING OTHERS.

STRESS

RELATED TO WORK

ANNOYANCE

ANNOYANCE

LOSS

LOSS/

UNREACHABLE OTHER

CONCERN FOR

VULNERABLE OTHER

LONELINESS: DIFFICULTY

WITH BEING ALONE

BEING REJECTED

$\operatorname{LOSS}(*)$

BEING REJECTED

BEING REJECTED

SELF-ASSERTION \& ANGER

CONCERN FOR

VULNERABLE OTHER

CONCERN FOR

VULNERABLE OTHER 
Table 8 continued

3. It was a difficult year for me, when I heard about the pregnancy, that my son would be a father. I felt a sense of guilt; I asked myself were I went wrong that made this situation possible ( $-\mathrm{O}: 2.00$ $3.671 .672 .75)$.

4. It was very intense to me, to notice that, in a sermon [not to me], my father could talk about what kept him busy and what gave him worries (-O: $\left.\begin{array}{llll}1.67 & 3.00 & 1.17 & 2.00\end{array}\right)$.

5. I see "lions and bears" [problems] everywhere. Especially since the death of my father, I experience fear, even a fear of death. My father is the person who gave rise to this fear, he transferred it to me. Fear is a concept that belongs to me (-O: $\left.\begin{array}{llll}1.00 & 3.67 & 1.17 & 2.33\end{array}\right)$.

6. The fact that I couldn't keep order in my classroom, that I didn't have the upper hand, stood in the way of me giving advice. I was ashamed because of it, it has a negative effect on my self-confidence. I can't say to someone else that he can't do the job, because it isn't credible (-O: 1.673 .33 $1.502 .58)$.

7. I felt abandoned when, as a girl of 10 years of age, I had to live with strangers for three weeks because my father suffered from a stress episode. I was crying in my bed at night, because I missed my parents very much (-LL: $17 \quad .83 \quad .17 \quad 3.75)$.

8. The four years as a teacher were very difficult for me. Those difficult years I had in the beginning POWERLESSNESS \& ISOLATION of my career, still influence my life. It was a very nasty period, I couldn't keep order in the class- (= LACK OF SELF-CONFIDENCE room, didn't have the upper hand. I didn't dare talk about it and had to cope on my own (-LL: 1.00 $1.67 \quad .834 .33)$.

P4: $+H H=6,+S=1,+O=5,-S=2,-O=3,-L L=6$. Male, age 51 .

1. Twenty-seven years later, I still feel an intense grief when I recall the illness of my deceased wife, when I recall saying goodbye to her, when I recall her death (-O: $\left.\begin{array}{llll}2.33 & 3.67 & .83 & 2.83\end{array}\right)$.

2. I was very disappointed and sad when my girlfriend chose another friend. I was very much in love with her. I would still like to have her in my life (-O: $83 \quad 3.17 \quad 1.83 \quad 2.75)$.

3. For the rest of the world I try to be the funny [name]. Even if I am sad. But as soon as I get home and are alone, I start crying. At these moments I feel very lonely and sad $(-\mathrm{O}: 1.33 \quad 2.50 \quad 1.67$ 2.50).

4. Especially after my divorce, I feel let down by friends and acquaintances. More and more, I was not invited to parties, friends came around less often. I feel disappointed and bitter by this behavior (-LL: .67 617 1.17 3.00).

5. I was very angry and sad when my girlfriend left me. I felt cheated by her when she finally choose for her family. I was very angry when I saw her and her husband close together by the gate, in order for me to see that everything was all right between them (-LL: .17 $\quad 17$.00 2.17).

6. I am afraid that I will be disappointed again. I lost my faith in women. All too often I experienced the pain of unrequited love. I am becoming suspicious towards women (-LL: .33 $\quad .83 \quad .50$ 2.42).

7. At this moment in time I am unhappy. I find it very difficult to be alone; not to be in a relationship. I don't have anyone just for myself, don't have a relationship for 5 years now. I miss "doing things together", like watching tv, sit next to each other on the couch, just not being alone (-LL: .17 $\quad .50$ .17 2.75).

8. My second spouse [..] has cheated on me with another man. We still are in contact with each other because the children should not be the victim of our troubles. I am very glad about that (-S: 1.17 $.00 .332 .08)$.

9. I hate my former colleague. In the past, I helped him to get the function of controller and now feel betrayed by him; he has left me in the lurch. When I needed him, he wasn't there for me (-S: 1.50 $\begin{array}{lll}.50 & .00 & 2.25)\end{array}$

P5: $+H H=14,+S=3,+O=0,-S=2,-O=2,-L L=11$. Female, age 51.

1. Lately, I think a lot about sickness and death and how I have to deal with that and also about how I have to deal with the people who are left behind (-O: $2.17 \quad 3.67 \quad 1.50 \quad 3.25)$.

2. What do I have to do to be able to talk about things like sickness and death? (-O: $1.502 .67 \quad 1.67$ $3.33)$.

3. My father forced his own way of life upon his children and didn't understand that we children also wanted to be heard. This made me angry and also very distressed (-LL: 2.17 2.00 1.67 4.58).

4. In high school, I had a lot of trouble with my classmates. It was clear that I didn't belong. I felt terribly lonely at that time (-LL: $\begin{array}{llll}1.67 & 1.00 & 1.00 & 5.00) \text {. }\end{array}$

5. I cannot understand and I never understood the fact that people close to you don't see that you are sad, especially mothers and their children (-LL: $1.17 \quad 1.00 \quad 1.00 \quad 4.92)$.

6. I got engaged and was severely restricted. For thirty years I struggled with my relationship - marriage. This resulted in a lot of sadness and tension (-LL: $2.17 \quad 1.67 \quad 2.17$ 4.58).

LOSS/

PROLONGED GRIEVING

LOSS/

UNREACHABLE OTHER

LONELINESS/

DIFFICULTY WITH BEING ALONE

BEING REJECTED

BEING REJECTED

FEAR OF REJECTION

LONELINESS/

DIFFICULTY WITH BEING ALONE

BEING DECEIVED

BEING DECEIVED

FEAR OF LOSS \& COMPASSION FOR OTHERS

FEAR OF LOSS \&

COMPASSION FOR OTHERS

DIFFICULT/DETACHED

RELATIONSHIP WITH PARENTS

LONELINESS:

ISOLATION

LONELINESS: ISOLATION/

LACK OF SUPPORT (OF MOTHER)

DISSATISFACTION WITH RELATIONSHIP 
Table 8. continued

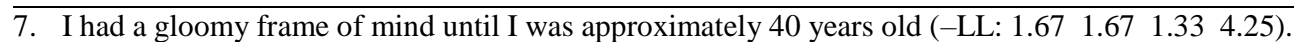

8. As a person seeking re-entrance into the labor market, I had to experience that I had built up only little resilience (-LL: $1.001 .17 \quad 1.17 \quad 4.00)$.

9. I have a lot of trouble with indifferent behavior. In my last job I experienced that people left me in

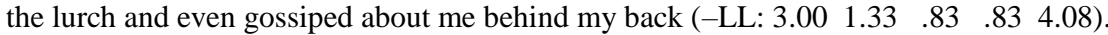

10. I am glad that I have been able to share the sadness about our divorce with my ex-partner and that AFFILIATION WITH OTHERS $(*)$ we were able to express each other's shortcomings (-S: $4.33 \quad 1.33 \quad 2.67 \quad 3.25)$.

Note. (*) Discrepancy between text and affect.

was having worries about her son becoming a father at a very young age $(2,-\mathrm{O})$, which made her feel guilty $(3,-\mathrm{O})$. In another $-\mathrm{O}$ valuation, she mentions her being intrinsically and excessively anxious, caused by her father (5). In addition, she's pondering over her lack of authority and shameful lack of self-confidence in her work as an advisor (6). Apparently, these states of 'generalized anxiety' $(5,-\mathrm{O})$ and 'frailty' $(6,-\mathrm{O})$ are associated with feelings of connection too $(\mathrm{O})$, possibly due to a self-pitying mood. In one valuation, she clearly expresses 'powerlessness and isolation' when unfolding a dismal period in her life being a teacher $(8,-\mathrm{LL})$.

The fourth person (P4) formulated a few $-\mathrm{O}$ valuations. They convey intense prolonged grieving over a deceased spouse (1), a still ongoing longing for an unreachable loved one (2), and the experiencing of deep loneliness when being alone $(3,-\mathrm{O})$. His difficulty with being alone is iterated in valuation (7), but now, apparently, the isolation is more felt (-LL). In several texts he describes how he has repeatedly

been disappointed in relationships $(2,4,5,8)$, which has resulted in a general distrust towards women and a fear of being rejected by them again (6). He also describes the bitter experience of the deterioration of former mutual friendships, after the divorce from his wife $(4,-\mathrm{LL})$. This feeling of being rejected by former friends is associated with isolation (-LL). Although in most texts he displays a depressed state of mind, in some valuations he expresses his anger, i.e., when thinking about the deceit of a former spouse $(8,-S)$ or former colleague $(9,-\mathrm{S})$.

The fifth person (P5) worded only two $-\mathrm{O}$ valuations and much more -LL valuations. In two valuations, she expresses her compassion for others who are expected to be confronted with the death of a loved one in the near future $(1,2$, both -0$)$. In other valuations she describes the detached relationship with her dominant father (3), her terribly lonely period in high school (4) and her mother's insensitivity at the time (5); in all of these valuations the theme of 'isolation' (-LL) is clearly present. She discloses that she had had a gloomy state of mind for a long time $(7,-\mathrm{LL})$, partly during marriage with her dominant restrictive partner (6, -LL). When she formulates a positively colored text about this ex-partner and their discussing each other's shortcomings during marriage, she reacts with anger $(10,-\mathrm{S})$, exposing a discrepancy between text ("I am glad") and affect $(\mathrm{N}>\mathrm{P})$. She also discusses her vulnerability when re-entering into the labor market $(8,-\mathrm{LL})$ and interpersonal problems in work relationships $(9,-\mathrm{LL})$.

In summary, in the texts of these 'preoccupied' attached persons, several anaclitic themes are discernible. Some may be considered typical $-\mathrm{O}$ themes, such as the texts referring to '(fear of) loss and bereavement' - see Table 8: P1(2, 3); $\mathrm{P} 2(1,2,6) ; \mathrm{P} 4(1,2) ; \mathrm{P} 5(1,2)$ - and those referring to 'concern for a vulnerable other': P1(4); P2(3); P3(1, 2, 3). All five persons formulated one or more texts $(-\mathrm{O}$ or $-\mathrm{LL})$ signifying '(a fear of) rejection': P1(6); P2(5, 7, 8); P3(4); $\mathrm{P} 4(4,5,6)$; P5(9). Another characteristic theme seems 'loneliness or difficulty with being alone' (dependency): two persons explicitly mention that they now have great difficulty with being alone: P2(4); P4(3, 7); and two other persons describe childhood experiences about abandonment and loneliness: P3(7); P5(4, 5). A final possible (but less) characteristic theme of this cluster may be 'feebleness and vulnerability', as two persons mention their lack of self-confidence in work situations: P3 $(6,8)$; P5 $(8,9)$. With respect to upbringing, several persons have subsumed a text implying rejection or lack of support from their parents: P1(6); P3(4, 5); P5(3, 5).

\section{Dismissive-avoidant cluster}

The first dismissive-avoidant person (Table 9: D1), formulated a reasonable number of $-\mathrm{O}$ valuations, which may be considered atypical of this prototype. He describes an intimate moment with his deceased father $(2,-\mathrm{O})$ and expresses his worries about his son, who is wasting his talents $(1,-\mathrm{O})$. In addition, he formulated several texts about alienation and lack of a sense of connection with others $(3,4,5,9)$. He describes that, from a young age, he has been feeling like a maverick, living in his own world $(3,-\mathrm{O})$ and that he still feels estranged and isolated not being able to be the person he really is $(4,-\mathrm{LL})$. He typifies himself as a "bitter, cynical person", who is very critical towards society in general (9, $-\mathrm{S})$, but also is regrettably aware that a vulnerable boy hides behind this cynical façade $(5,-\mathrm{LL})$. In two of the aforementioned texts he refers to his lack of 'a sense of authenticity' in relationships $(4,5)$, which is repeated when he argues that his work has been impairing the quality of his life for a long time $(8,-S)$. He formulates a few valuations related to his upbringing. In one valuation he argues that he has been betrayed by his parents, but it remains rather vague what he blames them for $(10,-\mathrm{S})$. In another valuation, he recalls an episode in which his mother had passed away and his father - being absorbed by his own grief - "forgot him" $(7,-S)$. He mentions that when his partner's children are around he feels isolated, powerless and annoyed $(6,-\mathrm{S})$. It seems that in some of these valuations he is predominantly describing a dejected state of mind $(6,8,9)$ or expressing a longing for contact (7), but nevertheless responds with anger $(-\mathrm{S})$ (cf. discrepancy between text and affect). 
D1: $+H H=10,+S=1,+O=0,-S=9,-O=5,-L L=3$. Male, age 50.

1. It hurts me and I feel powerless when I look at how my eldest son is doing. I have no influence on what happens to him. He has so many talents and doesn't use them at all (-O: $2.67 \quad 3.50 \quad .67$ 2.92).

2. When I found my father dead, I drank a beer with him on the couch. He had told me to do that and not dwell on his death for too long. I was very sad at the time, but I did toast him! Thanks Dad! (-O: $2.67 \quad 4.50 \quad$.00 2.50 ).

3. Already during my infancy I was considered to be an oddity. I was forward at a young age, read a lot of books and always wanted to know the ins and outs of things. I often deliberately retracted into my own private world (-O: $\left.\begin{array}{lllll}1.00 & 3.67 & 1.50 & 2.67\end{array}\right)$.

4. I often feel like a visitor from another planet. I have feelings of loneliness, of not being under-

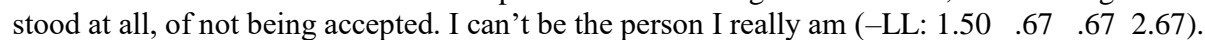

5. I regret that people think I am a harder person than I am. I have more emotions than people think. Beneath the seemingly secure person, there is an emotional small boy. I think (know) that I appear to be different from my true self (-LL: 1.17 1.00 1.17 2.33).

6. I feel alone, locked up, powerless, especially if my partner's children are around. They take up all the attention and space. They also take my space. I feel irritated too (-S: $\left.\begin{array}{llll}1.67 & .17 & .50 & 2.75\end{array}\right)$.

7. I was very sad because my father "forgot" me after the death of my mother. He was so involved in himself; he didn't give any attention to me (-S: $2.83 \quad 2.67 \quad .33 \quad 3.25)$.

8. My work has a negative impact on my quality of life. I can't be the teacher I want to be for 20

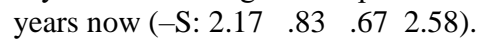

9. I have become a bitter, cynical person. I resent the unprofessionalism of people who are in positions where decisions can be taken without the knowledge to do so. I am cynical towards the society in general and the educational sector in particular (-S: $\left.\begin{array}{llll}2.83 & 1.17 & 1.00 & 2.58\end{array}\right)$.

10. I was raised with the idea that things would always get better. I feel betrayed by the people who

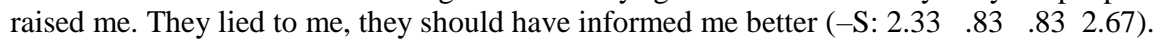

D2: $+H H=2,+S=7,+O=7,-S=1,-O=0,-L L=8$. Female, age 49 .

1. I miss the moments of contemplation in my life, by being too hasty and too busy (-LL: .00 .00 .001 .17 ).

2. At the age of 12 I stood among 1500 students I didn't know and with whom I didn't dare to start a conversation (-LL: $17 \quad .00 \quad .00 \quad 2.08)$.

3. As a child, I was very scared of my father because of his unpredictable anger attacks. The fear is still there, despite the fact that he is already dead for almost 20 years $(-$ LL: $.00 \quad .00 \quad .00$ 2.67).

4. My father was a perfectionist and a go-getter. He gave me the feeling that I did a lot of things just to get his approval (-LL: $00 \quad .00 \quad .00 \quad 2.00)$.

5. Due to the abrupt phase changes in my life, I had to start over and over again. Because of this there are no more friends in my life from a previous phase. This is a big loss, because I have no shared memories with anyone (-LL: 000000001.67 ).

6. I think of the demise of humanity as shockingly sad (-LL: .00 $\quad .00 \quad .00 \quad 1.58$ ).

7. I was very sad about the death of [name] (-LL: .00 $\quad .00 \quad .00 \quad 1.33$ ).

8. Because our marriage ended, after being together for 16 years, I lost my soul mate. I wasn't angry, but very sad. I can understand his choice (-S: $\left.\begin{array}{llll}1.33 & .00 & .00 & 2.00\end{array}\right)$.

D3: $+H H=13,+S=3,+O=1,-S=2,-O=0,-L L=4$. Female, age 45.

1. My father is a dominant, overruling, difficult man for himself and the people around him (-LL: $\begin{array}{llll}1.50 & 1.17 & 1.00 & 3.58) \text {. }\end{array}$

2. My mother is superficial, detached and insecure. I don't have a bond with my mother (-LL: 1.83 1.001 .33 2.67).

3. Already since my childhood, I feel very responsible for the atmosphere at home (-LL: $1.50 \quad .83$ .83 3.92)

4. I am still angry that for a long time I invested in a relationship that didn't really feel good (-LL: $\begin{array}{llll}.67 \quad 67 & .50 & 4.25) \text {. }\end{array}$

5. Ending my relationship brought me a lot of grief and feelings of guilt (-S: $\left.\begin{array}{lllll}2.67 & 1.33 & 2.00 & 2.83\end{array}\right)$.

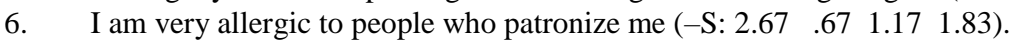

CONCERN FOR

VULNERABLE OTHER

LOSS/BEREAVEMENT

ISOLATION \& PREFERENCE FOR SOLITUDE

ISOLATION \& ALIENATION

ISOLATION \&

ALIENATION

ISOLATION \& POWERLESSNESS $(*)$

BEING REJECTED

(BY PARENTS) $(*)$

POWERLESSNESS \& LACK OF EXISTENTIAL MEANING $(*)$

POWERLESSNESS \& LACK OF

EXISTENTIAL MEANING $(*)$

BEING DECEIVED

(BY PARENTS)

LACK OF

EXISTENTIAL MEANING

TRAUMA:

BEING ISOLATED

TRAUMA/

NEGLECT IN CHILDHOOD

DIFFICULT/DETACHED

RELATIONSHIP WITH PARENTS

LOSS \& ISOLATION $(*)$

DEPRESSED STATE

LOSS/BEREAVEMENT (*) LOSS (*)

DIFFICULT/DETACHED

RELATIONSHIP WITH PARENTS

DIFFICULT/DETACHED

RELATIONSHIP WITH PARENTS

PLEASING OTHERS

ANGER (*)

GUILT (*)

ANGER

Table 9 continued next page 
D4: $+H H=11,+S=15,+O=0,-S=6,-O=0,-L L=4$. Male, age 56.

1. I never expected that [name] would leave me/divorce me. When she told me that she went away I was completely at a loss, I had no idea she didn't love me anymore (-LL: $\left.\begin{array}{llll}33 & .17 & .00 & 4.33\end{array}\right)$.

2. I frequently miss [name]; her cheerfulness and femininity. She remains the leading thread running through my life, despite the fact that for a couple of years now I have been living together with someone else (-LL: $.50 \quad .00 \quad .00 \quad 4.42)$.

3. The 7 years after [name] were lonely and dreadful, even when I knew my present girlfriend as a good friend there was that lonely feeling of abandonment (-LL: .67 $1.17 \quad .83 \quad 4.50)$.

4. The lack of interest my mother showed towards my girlfriends was very annoying to me, $X$ who BEING REJECTED (BY PARENTS) was my very first girlfriend wasn't allowed to stay for dinner. My mother's idea was that no

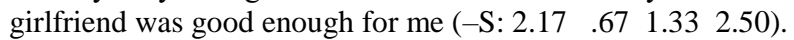

5. Work safety was disregarded; it goes against my sense of justice. I was very angry about that! Because of economic/cost-saving work, I had to keep my mouth shut about a defective material. But I didn't do that (-S: 3.83 1.33 .83 3.00).

6. The management wasn't enough interested in me: they did not want to know what was really going on inside of me. They were too arrogant and too concerned with themselves and their power. That caused me a lot of anger (-S: 4.83 .33 1.17 2.42).

7. I opposed the incoming yuppies in our organization. Hardly 23 years old and barely without a diaper, but very arrogant. They thought they knew everything and could tell us how to do it (S: 5.00 .001 .331 .83$)$.

8. I feel rejected by [name organization] after my burn-out. I feel like I am treated as a disposable item; too old: then you have to go (-S: $\left.\begin{array}{llll}3.67 & 17 & 1.83 & 2.08\end{array}\right)$.

9. I am amazed how we all take part in the system; look at the highways at 6 am! Like fools behind each other and getting stuck in traffic (-S: 2.17 .33 1.00 1.92).

$\underline{D 5}:+H H=12,+S=5,+O=0,-S=5,-O=1,-L L=6$. Female, age 43.

1. My biggest fear is that something happens to my daughter. Her health has been fragile and by means of my intuition I saved her a couple of times in de nick of time (-O: $\left.\begin{array}{lllll}1.83 & 2.33 & .67 & 3.42\end{array}\right)$.

2. It cuts me to the bone that my daughter [..] has been bullied in elementary school (-LL: 1.83 $2.33 \quad 67$ 4.08).

3. My mother is the center of the earth. My whole life I had to accommodate myself to her (-LL: $\begin{array}{llll}.67 & .33 & .17 & 4.75) \text {. }\end{array}$

4. Born for a dime, I will never be a quarter. That is how I was raised (-LL: $1.00 \quad 1.00 \quad .50$ 4.17).

5. Taking care of my daughter, is sometimes very hard. Because of her diet, I always need to cook or bake especially for her. If we go somewhere, I always have to think and plan ahead. I sometimes feel guilty about these feelings because it could be much worse. What irritates me, is how easy bystanders handle this (-LL: $1.83 \quad 2.00 \quad 1.00 \quad 4.50$ ).

6. I have never had a job in which I was challenged, stimulated. Until now I always was an underachiever, which several times led me to the brink of overexertion/burn-out. To find a challenge, I accepted working at several projects and management functions which in turn resulted in lack of time (-LL: $1.00 \quad .50 \quad .67 \quad 4.58)$.

7. I never received validation from my mother and I am never good enough for her. This caused BEING REJECTED (BY PARENTS)

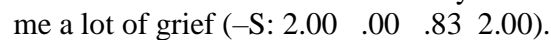

8. A psychologist suggested to me to take an IQ-test. The result shocked me because I turned out to be gifted. In a flash, all my missed chances rushed past me. I have been very sad about that (S: $4.17 .501 .67 \quad 4.17$ ).

$\left.\begin{array}{lllll}9 . & \text { Everything in my life, I figured out myself, I had to do myself ( }-\mathrm{S}: 3.83 \quad .00 & 1.50 & 3.00\end{array}\right)$.

Note: (*) Discrepancy between text and affect.

The second person (D2) predominantly formulated - LL valuations. She describes her traumatic youth, in which she had to deal with the unpredictable aggressive outbursts of her father $(3,-\mathrm{LL})$, but that she, nevertheless, also needed his recognition $(4,-\mathrm{LL})$. She recalls a traumatic experience when being at school for the first time $(2,-\mathrm{LL})$. In one text, she verbalizes a lack of existential meaning in her life (1,LL) and shows a pronounced downhearted state of mind when referring to the end of humanity $(6,-\mathrm{LL})$. When she remembers the grief related to a late friend $(7,-\mathrm{LL})$, she doesn't report any feelings for connection $(\mathrm{O}=0.00)$. Similarly, when she's thinking about the many lost friends from the past $(5,-\mathrm{LL})$ or recalling the sadness of her broken marriage $(8,-\mathrm{S})$, she doesn't respond with a longing for contact at all $(\mathrm{O}=0.00$, in all texts $)$. In our view, these valuations expose a discrepancy between text and affect.

The third person (D3) formulated only very few negative valuations. She articulates the problematic relationships with her domineering father $(1,-\mathrm{LL})$ and her aloof mother $(2,-\mathrm{LL})$. It is not so clear what she means by saying that she 
felt responsible for the atmosphere at home $(3,-\mathrm{LL})$, but probably alludes to her desire to please. In two texts, she describes her feelings with respect to the ending of a longterm relationship $(4,5)$. Sometimes she can still become angry when she realizes that the investment in this relationship was futile $(4,-\mathrm{LL})$. In contrast, when she describes her dejected feelings during the breakup, she reacts with anger $(5$, $-\mathrm{S}$ ). Hence, it seems that for these two valuations the affective meaning has been interchanged (cf. discrepancy). In the last negative valuation, she verbalizes a general anger towards condescending people $(6,-S)$.

The fourth person (D4), like D2 and D3, didn't include any explicit $-\mathrm{O}$ valuation in his valuation system, but the first three valuations clearly pertain to 'longing and loss'. In these valuations he communicates how surprised he was when his former wife left him, because she apparently didn't love him anymore $(1,-\mathrm{LL})$, that after their divorce, for a very long time, he felt horribly lonesome $(3,-\mathrm{LL})$, and that even nowadays he still misses his ex-wife $(2,-\mathrm{LL})$. It is surprising that in valuation 2 , in which he truly discloses a deep longing for his ex-wife, the longing for connection is so low $(\mathrm{O}=0.00)$ (cf. discrepancy). In valuation 3 he reflects about a long period of grief over this broken relationship, but the striving for union hardly outweighs the striving for self-enhancement ( $\mathrm{S}=0.67, \mathrm{O}=1.17$ ) (cf. discrepancy). Apparently, when remembering these periods in his life, the feeling of isolation seems to prevail (-LL). The self-narrative as a whole was dominated by negative $-\mathrm{S}$ valuations, mainly related to work $(5,6,7,8)$. In two of these $-S$ valuations he describes the frustration with the management that did not take work safety seriously $(5,7)$. In two other $-S$ valuations, he discloses how the management displayed little understanding for his problems (6), and how he eventually was dismissed after a period of burn-out (8). Another $-\mathrm{S}$ valuation pertains to his mother who showed a distinct disinterest towards a girlfriend of his $(4,-\mathrm{S})$. He also alludes to the existential emptiness of his and other people's lives $(9,-\mathrm{S})$.

The fifth person (D5) formulated several texts about her fragile daughter $(1,2,5)$. She discloses that, although she is genuinely over-concerned for her daughter's health $(1,-\mathrm{O})$, caring for her is very demanding too $(5,-\mathrm{LL})$. She expresses a profound pain and powerlessness, when remembering her daughter being bullied in elementary school $(2,-\mathrm{LL})$. When she's thinking about her own childhood $(3,4,7,9)$, she is particularly envisioning her (dominant) mother to whom she had to accommodate to $(3,-\mathrm{LL})$, and for whom she never was good enough $(7,-S)$. She refers to the lack of support and stimulation at home $(9,-\mathrm{S})$ and accentuates that she has been raised with a "sense of inferiority" $(4,-$ LL). Only at an older age, when she found out that she was highly gifted (not inferior), she realized that she had missed many chances in her life (8); Affectively, it is not the "sadness" as mentioned in the text (8), but rather the anger that prevails (-S) (cf. discrepancy). Not knowing that she was gifted seems to explain her initial underachievement in work and her seeking challenges in all sorts of projects and management functions $(6,-\mathrm{LL})$.

In summary, in the texts of these 'dismissive-avoidant' attached persons, not only introjective but also anaclitic themes are visible. Four persons highlight a lack of existential meaning in their life and/or dissatisfaction in their work - D1 $(8,9)$; D2 (1); D4 $(8,9)$; D5 $(6,8)$ - which may be considered a typical introjective theme. In addition, all five persons have subsumed a text in which they disclose (anaclitic) issues related to isolation and loneliness: D1 $(3,4,5$, 6); D2 (2, 5, 8); D3 (1, 2); D4 (1, 2, 3); D5(9). It appears that some persons have difficulty with recognizing or expressing feelings of connection where it would be appropriate to do so: D2 $(5,7,8)$; D4 $(1,2,3)$. Another kind of distortion is visible in texts where persons are describing a dejected state of mind (-LL) but affectively responding with anger $(-\mathrm{S})-$ D1 (6, 7, 8, 9); D3 (5); D4 (8); D5 (8) - which corresponds with the prevailing theme of this cluster. With respect to upbringing, all five persons have subsumed one or more texts implying (persistent) neglect, rejection or lack of support by their parents: D1 (10); D2 (3, 4); D3 (1, 2); D4 (4); D5 (4, $7,9)$; In some cases, the tone of these texts is remarkably bitter (D1, D2, \& D3).

\section{Fearful-avoidant cluster}

The first fearful-avoidant attached person (Table 10: F1), formulated, like most persons allocated to this group, a preponderance of -LL valuations. In two valuations, she mentions that her mother never showed any appreciation towards her (1, -LL) and never accepted her how she was (4, $-\mathrm{LL})$. She discloses that she has great difficulty in sharing her feelings with someone and trusting other people $(5,-$ LL), and reveals to suppress or dissociate her emotions by playing all sorts of emotionless roles $(3,-\mathrm{LL})$. In addition, she formulates several texts related to (work and private) relationships. In one of these texts, she describes the powerlessness in her effort to change things $(6,-\mathrm{LL})$. She elaborates that she, being afraid of failure, displays a perfectionistic mindset $(8,-\mathrm{S})$ and is expecting a similar attitude from others $(7,-S)$. Needing the validation of others $(7)$, she realizes that she has difficulty with setting clear boundaries for herself, because she doesn't want to disappoint anyone $(9,-\mathrm{S})$.

The second person (F2) of this cluster, formulated several -LL valuations pertaining to his fear of intimacy $(2,3$, 4). He uncovers that he feels vulnerable when others come close to him (2) and is ashamed to show his emotions to others (4), although he is fully aware that this has made his life very difficult (3). He summarizes a rather despondent state of mind by wondering with whom he has a warm and intimate relationship $(5,-\mathrm{LL})$ and uttering the strong wish to enjoy daily life more $(6,-\mathrm{LL})$. The single $-\mathrm{O}$ valuation pertains to a somewhat self-pitying mood, in which weak pupils are reminding him of himself when he was young (1). The single $-\mathrm{S}$ valuation refers to his dislike of dominant and manipulative persons (7).

The third person (F3), formulated several -LL valuations about her miserable childhood $(2,3,4)$. She remembers the loveless relationship between her parents all too well (3) and is disgusted by the recollection of the loveless parental home of her youth (4). In addition, she is blaming her mother for confronting her from an early age with her own fears (2). She discloses that she is painfully aware of her own shortcomings in intimate relationships, which is most tangible in the relationship with her children $(1,-\mathrm{O})$. She also displays a self-perfectionist attitude with respect to work $(5,-\mathrm{LL})$ and phrases a rather pathetic motto expressing a generalized helpless mood $(6,-\mathrm{S})$. 
$F 1:+H H=1,+S=5+O=3,-S=4,-O=0,-L L=13$. Female, age 53.

1. It hurts me, that I never got any appreciation from my mother who is now 81 years of age (-LL: $\left.\begin{array}{llll}1.00 & .67 & .17 & 2.75\end{array}\right)$.

2. I hate being as shy as I am. It makes me miss chances. I usually don't act or procrastinate, because I don't dare to act (-LL: $17 \quad .00 \quad .00 \quad 2.58$ ).

3. I can play many roles without emotions, because these roles are expected of me. I would like to step out of that role. Every now and then, I try to step out of the role that I play, but others don't appreciate that because I react too emotionally then $\neg\left(\begin{array}{lllll}- \text { LL: } & .83 & .00 & .50 & 2.83\end{array}\right)$.

4. In the past couple of years, my mother occasionally indicated that she considered me to have been a difficult child. I think that this is because I sometimes wanted changes and I wanted to be independent. I don't understand that very well, because I always thought that I was an easy child in my family (-LL: $67 \quad .00 \quad .00 \quad 1.75$ ).

5. I am afraid that it comes back to me if I tell somebody about my feelings or emotions. I don't trust anybody, because I am afraid they tell others or give a negative meaning to it (-LL: $.83 \quad .50$ 1.002 .92 .

6. Time and again I come across things I would like to change, both in my work and in my relationships. I wouldn't know how to make these changes. I also don't know who can help me make changes (-LL: $.17 \quad .00 \quad .50 \quad 2.42$ ).

7. From my co-workers I expect the same accomplishments and efforts that I expect from myself. Of course I realize that not everybody has the same need to accomplish things. I need the validation my work gives me (-S: $2.83 .67 \quad 1.83$ 3.08).

8. I don't dare to fail. Whatever I start, I have to finish. Preferably with a good result (both at work and in my private life) (-S: $\left.\begin{array}{llll}3.33 & .00 & 1.83 & 2.83\end{array}\right)$.

9. I know I have to set boundaries sooner. But I don't want to disappoint anyone. I am learning to handle this better (-S: $\left.\begin{array}{lllll}1.67 & .00 & 1.67 & 2.50\end{array}\right)$.

F2: $+H H=8,+S=5,+O=1,-S=1,-O=1,-L L=7$. Male, age 31 .

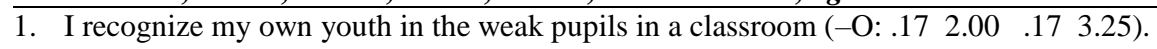

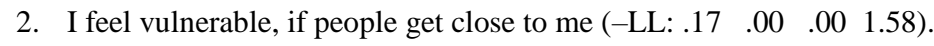

3. I can make my life difficult by keeping too much to myself. This is something I do during my whole life this far (-LL: $.17 \quad .00 \quad .00 \quad 2.33$ ).

4. I am ashamed to show my emotions (-LL: .00 $\quad .00 \quad .00 \quad 1.58)$

5. With whom do I have a warm and close bond? (-LL: .00 $\quad 00 \quad .33$ 2.67).

6. I would like to enjoy life as it unfolds much more (-LL: .00 $\quad .00 \quad .00 \quad 1.33)$.

7. I don't like dominating personalities. People who cunningly play with other people. I show resistance to people like that (-S: $\left.\begin{array}{llll}1.67 & .00 & .17 & 2.42\end{array}\right)$.

F3: $+H H=5,+S=7,+O=0,-S=1,-O=1,-L L=5$. Female, age 45.

1. I have the feeling that I fall short in intimate relationships and that is very painful to me. This is especially apparent in the relationship with my children (-O: $\left.\begin{array}{lllll}1.00 & 2.50 & .67 & 3.50\end{array}\right)$.

2. I very much blame my mother, that, from a very early age on, she used me as a safety valve for all her fears (-LL: $1.00 \quad 1.00 \quad .50 \quad 3.58)$.

3. I absolutely wanted a different relationship with a man, compared to the loveless relationship of my parents (-LL: $1.33 \quad .83 \quad .83 \quad 3.50$ ).

4. My perception of my parental home has always been one of intense disgust. I perceived my youth as very meager and loveless (-LL: $\begin{array}{lllll}1.17 & 1.00 & 1.00 & 3.67) .\end{array}$

5. I find it difficult to work on a [relatively low] professional level, because I cannot display my whole self in this setting. I want more depth in my work (-ᄀLL: $\left.\begin{array}{llll}1.33 & 1.33 & 1.50 & 3.00\end{array}\right)$.

6. My motto has always been: "You have to do it on your own in life, there's no one who takes care of you" (-S: $2.33 \quad$.33 $1.00 \quad 2.00)$.

F4: $+H H=15,+S=13,+O=0,-S=0,-O=0,-L L=19$. Female, age 39.

1. The relationship with my mother is a black box that needs to be examined in the near future (-LL: $\begin{array}{lllll}1.00 & 2.00 & .67 & 3.92)\end{array}$

2. Because of sexual intimidation in the beginning of my career, I still keep (too) much distance to my colleagues, especially the male ones (-LL: .17 $\quad .00 \quad .00 \quad 4.25)$.

3. In my work, I don't take a vulnerable position (any more) (-LL: $\left.\begin{array}{llll}1.00 & .50 & .50 & 3.33\end{array}\right)$.

4. In my youth, I strongly accommodated myself to what I thought my surroundings expected from me (-LL: $1.001 .33 \quad 1.00 \quad 4.17$ ).

\section{BEING REJECTED \\ (BY PARENT) \\ POWERLESSNESS}

DISSOCIATION/

SUPPRESSION OF EMOTIONS

BEING REJECTED

(BY PARENT)

FEAR OF INTIMACY \& DISTRUST IN OTHERS

POWERLESSNESS

SELF-CRITICAL PERFECTIONISM (IN WORK)

SELF-CRITICAL PERFECTIONISM

PLEASING OTHERS

CONCERN FOR VULNERABLE

OTHER \& POWERLESSNESS

FEAR OF INTIMACY \&

DISTRUST IN OTHERS

AVOIDANCE OF INTIMACY

DISSOCIATION/

SUPPRESSION OF EMOTIONS

ISOLATION

LACK OF PLEASURE

ANGER \& ANNOYANCE

DIFFICULTY WITH

INTIMACY \& GUILT

TRAUMA/

NEGLECT IN CHILDHOOD

TRAUMA/

NEGLECT IN CHILDHOOD

TRAUMA/

NEGLECT IN CHILDHOOD

SELF CRITICAL PERFECTIONISM

(IN WORK)

LACK OF SUPPORT \& ISOLATION

TRAUMA/NEGLECT IN CHILDHOOD \& DISSOCIATION TRAUMA

DEFENSIVE SEPARATION -

DISTRUST IN OTHERS

PLEASING OTHERS 
Table 10 continued

5. For a big part of my life, I neglected the signals my body send me. I always went far across my boundaries (-LL: $1.00 \quad .00 \quad .83 \quad 3.75$ ).

6. Right now, I don't have the energy to be or want to be in the vicinity of my mother (-LL: .83 $1.33 \quad 83 \quad 3.50)$.

7. Right now, I experience limitations I never experienced before [burn-out]. Usually I was busy

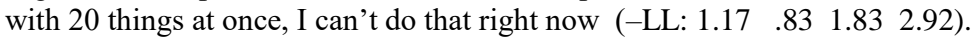

8. For a long time now, I approach almost anything in a rational way. In this way I have, thoroughly

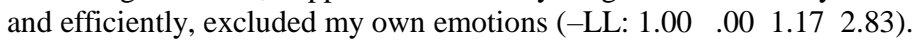

\author{
DISSOCIATION (IGNORING \\ PHYSICAL SIGNALS) \& \\ PERFECTIONISM \\ LACK OF ENERGY \\ LACK OF ENERGY \& \\ PERFECTIONISM \\ DISSOCIATION/ \\ SUPPRESSION OF EMOTIONS
}

F5: $+H H=1,+S=8,+O=5,-S=0,-O=3,-L L=11$. Female, age 45.

1. I have a symbiotic relationship with my mother. I took care of my mother so she could be there for me. I resent that I can't show her who I really am (-O: $\left.\begin{array}{llll}-17 & 2.00 & .00 & 3.00\end{array}\right)$.

2. The suicide attempt of my sister has had an enormous impact on our entire family (-O: .00 1.00 $.001 .67)$.

3. I find it poignant that my oldest daughter was shut out at the end of primary school. This has hurt me a lot (-O: .00 1.00 .00 1.75).

4. I find it shocking that my former husband [...] has cast me aside. I gave [him] much more than he gave me (-LL: .00 $\quad .00 \quad .00 \quad 1.42)$

5. To feel good, I searched for harmony all my life. I have always accommodated to my surroundings (-LL: $.00 \quad .00 \quad .33$ 1.83).

6. For a long time, I felt guilty for not feeling in contact with my father (-LL: .00 $\quad .00 \quad .00 \quad 1.67)$.

7. Towards my youngest daughter, I feel guilty for not having been able to care for her in her first year of life and not have given her the love I wanted to give to her (-LL: .00 $\quad .00 \quad .00 \quad$ 1.33).

8. I find it difficult to indicate my boundaries. I feel very guilty if I do (-LL: $\left.\begin{array}{lllll}67 & .00 & .00 & 2.42\end{array}\right)$.

9. I am afraid of the feeling that there are only few people who love me as I am. I am afraid that I am "not good, nice etc. enough" for others (-LL: .00 $\quad .00 \quad .00 \quad 1.33$ ).

10. Losing my relationship is one of the most painful experiences in my life (-LL: .00 $\quad .00 \quad .00$ $1.25)$.

\section{NEGLECT IN CHILDHOOD \& PARENTIFICATION \\ TRAUMA/ \\ FEAR OF LOSS \\ CONCERN FOR \\ VULNERABLE OTHER \\ BEING REJECTED}

PLEASING OTHERS

GUILT

GUILT

\section{PLEASING OTHERS \& GUILT \\ ISOLATION \& \\ PLEASING OTHERS}

LOSS/BEING REJECTED
The self-narrative of the fourth person (F4) contained a great many -LL valuations. In some of these, she discusses her childhood experiences and the difficult relationship with her mother. She stresses that, at the moment, she's avoiding contact with her mother $(6,-\mathrm{LL})$ and, she denotes - by using a metaphor of a (closed) "black box" - that she actually doesn't want to think about the difficult relationship with her $(1,-$ LL). She recalls her being docile and very accommodating in her youth $(4,-\mathrm{LL})$. In several noteworthy texts, she describes how she, after having exhausted her body for a long time $(5,-\mathrm{LL})$, now she is bumping up against her own limits $(7,-\mathrm{LL})$. In addition, she articulates that she has the tendency "to approach almost anything in a rational way" and is able to thoroughly suppress her own feelings $(8,-$ LL). A traumatic experience in the beginning of her career $(2,-\mathrm{LL})$ has led her to distrust male colleagues $(3,-\mathrm{LL})$.

The fifth person (F5) was one of the few fearful-avoidant attached persons who formulated a number of $-\mathrm{O}$ valuations $(1,2,3)$. One of these valuations is about her family's longterm concern for her vulnerable sister (after her suicide attempt) $(2,-\mathrm{O})$. In another $-\mathrm{O}$ valuation she recollects how she felt when her daughter was being bullied at school (3,$\mathrm{O})$. She discloses that she used to take care of her mother, with whom she still has "a symbiotic relationship" $(1,-\mathrm{O})$; In contrast, she hasn't felt any connection at all with her father, which made her feel guilty $(6,-\mathrm{LL})$. In several valuations she illustrates how she has the tendency to please others for fear of being rejected $(4,5,8,9)$. She uncovers how she has searched harmony her whole life by accommodating to others $(5,-\mathrm{LL})$, that she has difficulty with setting boundaries $(8,-\mathrm{LL})$ for fear of not being liked $(9,-\mathrm{LL})$. When recalling the "shocking" rejection by her husband (4, -LL), she describes this loss as one of the most painful experiences in her life $(10,-\mathrm{LL})$. Finally, in one valuation she expresses her guilt about not being able to care for her new born daughter ( $7,-$ LL).

In summary, in the texts of these 'fearful-avoidant' attached persons, two related introjective themes catch the eye, viz. 'fear and avoidance of intimacy' F1 (5); F2 (2, 3); F3 (1) and 'dissociation or suppression of emotions': F1 (3); F2 (4); F4 (8). In addition, three persons formulated one or more texts (-S or $-\mathrm{LL})$ signifying 'pleasing others', which is an anaclitic theme: F1 (9); F4 (4); F5 $(5,8,9)$. This pleasing others seems connected with a difficulty with the setting of clear "ego-boundaries": F1 (9); F4 (5); F5 (8). Some persons explicitly refer to self-critical perfectionism in work F1 $(7,8)$; F3 (5) - and one person seems to be implying a perfectionistic attitude when she was exhausting her own body and being extremely busy: F4 $(5,7)$. With respect to upbringing, four persons worded recollections about neglect, rejection or lack of support by their parents or even trauma: F1 (1, 4); F3 (2, 3, 4, 6); F4 (1); F5 (1).

\section{DISCUSSION}

The findings of the first study indicate that Self, Other, Positive and Negative affect (as experienced in recent daily life) 
display meaningful relationships with the higher-order Anxiety-Avoidance-Control scales, but the expected theoretical relationships became only clearly 'visible' when the variables were graphically integrated in a two-dimensional representation. As expected, all three higher-order scales were positively correlated with Negative affect. However, contrary to our expectations, Anxiety was not positively correlated with Other affect, nor was Avoidance with Self affect. Moreover, multiple regression analyses revealed that $\operatorname{Self}(\beta$ $=-.35)$ and Negative affect $(\beta=.31)$ were the only significant predictors of Anxiety; Other $(\beta=-.28)$ and Negative affect $(\beta=.31)$ were the only significant predictors of Avoidance. Hence, it seems that attachment anxiety is not characterized by a 'high striving for connection (combined with high negative affect)' but rather by a 'low striving for self-enhancement (combined with high negative affect)'. Furthermore, the results suggest that attachment avoidance is not characterized by a high 'striving for self-enhancement (and high negative affect)' but rather by a 'low striving for connection (and high negative affect)'.

An additional multivariate perspective on the data was obtained by employing a concept mapping technique (socalled hexagon analysis), with which the lower-order personality scales were being projected within the boundaries of a hexagonal frame representing the six valuation types. By using this technique, the whole pattern of correlations of each attachment personality scale with the four SCM affectscales was being taken into account. The depiction revealed that there were two distinct clusters. The first 'anaclitic' cluster consisted of three anxiety subscales which were projected in the vicinity of the -O type. This indicates that anaclitic aspects (i.e., concern what others think, pleasing others) are associated with the SCM theme of 'unfulfilled longing and loss' $(-\mathrm{O})$, alluding to a friendly-submissive interpersonal orientation (Van Geel, 2000). The second 'introjective' cluster consisted of the avoidance, distrust, and control scales, which were localized close to the $-\mathrm{LL}$ and $-\mathrm{S}$ types. This implies that these personality aspects are associated with themes of 'powerlessness and isolation' (-LL) or 'anger and opposition' (-S), involving a mixture of submissive and cold-disconnected interpersonal orientations.

In the second study, the attachment-personality measures were correlated with the percentages of valuation types (as extracted from each SCM grid). As expected, all three higher-order personality scales were positively correlated with the percentage of -LL valuations. This implies that people with a large number of this kind of valuations experience higher levels of attachment anxiety and attachment avoidance in their relationships and display a higher need for control. Therefore, we propose that the number of valuations about 'powerlessness and isolation' (-LL) can best be interpreted as a general vulnerability factor related to depression. The results regarding the higher-order scales, further signify that the number of $-\mathrm{S}$ valuations may indicate specific introjective vulnerability, although it only positively correlated with need for control (not with avoidance). In addition, the number of $-\mathrm{O}$ valuations may be conceived of as a specific anaclitic vulnerability factor, as it correlated positively with attachment anxiety. Hence, it appears that a large number of one of the 'ambiguous' valuations ( $-\mathrm{S}$ or O) may amount to specific vulnerabilities. This idea was corroborated by the canonical correlation analysis, in which the lower-order personality scales were analysed.

The canonical correlation analysis resulted in three distinct variates. One of the variates disclosed that the number of valuations about 'powerlessness and isolation' (-LL) was associated with the three anaclitic as well as the three introjective features. This substantiates the notion that an intensified sense of 'powerlessness and isolation' is a sign of a general psychopathological vulnerability (related to depression). A second variate revealed that the number of valuations about 'anger and opposition' $(-S)$ was associated with introjective features such as distrust and control, thus indicating a specific introjective vulnerability. A third variate showed that the number of valuations about 'unfulfilled longing and loss' $(-\mathrm{O})$ was associated with anaclitic features (pleasing and dependency), signalling a specific anaclitic vulnerability.

With the aid of cluster analysis, we subdivided the dataset into four clusters, cogently representing the four attachment prototypes. The majority was classified as secure (51\%), followed by dismissive-avoidant (21\%), fearfulavoidant $(16 \%)$ and preoccupied (12\%). These percentages are comparable to those reported by Stein et al. (2002) who used several attachment measures to classify young adolescents from a community sample $(N=115)$. In a sample of young university students $(N=470)$, Feeney et al. (1994) clustered fewer persons as secure and fearful-avoidant and more as preoccupied and dismissive-avoidant. In the study of Brennan et al. (1998), undergraduate psychology students $(N=1,086)$ were more evenly distributed among the attachment prototypes. In our study, the fearful-avoidant cluster was characterized by a large amount of -LL and small amount of $+\mathrm{HH}$ valuations. More specifically, the people in this cluster formulated approximately $15-20 \%$ more -LL valuations (and $15-20 \%$ less $+\mathrm{HH}$ ) than the other three attachment clusters. This indicates that a heightened sense of 'powerlessness and isolation' is associated with 'general attachment insecurity' (cf. fearful-avoidant attachment). The dismissive-avoidant cluster phrased somewhat more $-\mathrm{S}$ valuations than the other three clusters, signalling that they tend to be more annoyed or hostile towards others. The preoccupied attached persons included somewhat more $-\mathrm{O}$ valuations and less $+\mathrm{S}$ valuations. More specifically, the people in the preoccupied cluster formulated approximately $5 \%$ more $-\mathrm{O}$ valuations (and $10 \%$ less $+\mathrm{S}$ ) than those of the other clusters. So it seems that the experience of unfulfilled longing has a prominent place in the self-narratives of preoccupied attached persons.

When considering the whole profile of percentages of valuation types of the four clusters (See Table 7), it appears that fearful-avoidant attachment can be differentiated from the other three attachment prototypes by looking at the proportions of the $+\mathrm{HH}$ and $-\mathrm{LL}$ types; regarding the proportions of the $-\mathrm{O},+\mathrm{S}$ and $-\mathrm{S}$ types, a further distinction can be made between preoccupied and dismissive-avoidant attachment. Hence, if during an SCM self-investigation, a person has included many -LL profiles (say > 25\%), many -O (10$15 \%)$ or many $-\mathrm{S}(10-15 \%)$, this may indicate a fearfulavoidant, preoccupied, or dismissive-avoidant orientation, respectively. However, based on the numerical features of the SCM self-narrative alone, 'dismissive-avoidant' attached 
persons may be difficult to distinguish from securely attached persons, in that they tend to formulate an equal number of $+\mathrm{HH},+\mathrm{S},+\mathrm{O},-\mathrm{O}$ and $-\mathrm{LL}$ valuations; the only difference is that they formulate somewhat more $-\mathrm{S}$ valuations (See Table 7). Perhaps, dismissive-avoidant attached people are able to present themselves in an SCM self-investigation as securely attached - they also view themselves that way; having only few problems and feel "all is well" (Wallin, 2007) — without being aware that they are inclined to being annoyed, hostile, and competitive (cf. somewhat more $-\mathrm{S}$, Table 7) and have a tendency to avoid intimacy and cherish their independency more than securely attached persons do (cf. introjective features in Table 6). In an SCM counselling session, a provisional classification into one of the insecure attachment prototypes may give rise to include additional relevant themes for discussion. Yet, ideally, this should be carried out by combining the numerical features (i.e., percentages of valuation types) with the content of valuations, i.e., with the sentences a person has formulated during his or her self-investigation. These texts will undeniably contain clues that point to one of the three insecure attachment orientations.

In the third study, we shifted our focus to the texts formulated by the 'insecurely' attached persons. For five persons from each of the 'insecure' attachment clusters, we were able to detect meaningful anaclitic and introjective themes in their $-\mathrm{S},-\mathrm{O}$ and $-\mathrm{LL}$ valuations. In the preoccupied cluster, most persons formulated several $-\mathrm{O}$ texts (see Study 2), in which people typically articulated experiences related to 'loss or bereavement' or 'concern for the well-being of a vulnerable other'. Other distinctive anaclitic issues, in $-\mathrm{O}$ texts or $-\mathrm{LL}$ texts, were '(a fear of) rejection' and 'loneliness or difficulty with being alone'. There was also a sense of inadequacy and low self-confidence in some of the texts. Taken together, in the texts of most of these persons we can find traces of a friendly-submissive interpersonal orientation, putting them at risk to develop an anaclitic depression, which is "characterized by feelings of loneliness, helplessness, weakness and fears of abandonment" (Luyten, Blatt et al., 2005, p. 76). The first preoccupied person P1 (see Table 8) seems at risk, because he has difficulty to stand up for himself in private relationships $(5,6)$ as well as in his work relationships $(7,8$, cf. submissive orientation) and is inclined to experience intense grief after loss $(2,3) .{ }^{1} \mathrm{P} 2$ (See Table 8) may be at serious risk, because she displays a strong self-sacrificing tendency - e.g., she kept nursing her sick husband $(2,3)$ even when he was rejecting her $(7,8)$ (cf. submissive orientation) and is often struggling with feelings of loneliness when she is on her own $(1,4)$. P3 is at risk to develop depressive complaints, because she is worrying about other people's welfare $(1,2,3)$, seriously lacking confidence in her work $(6,8$, cf. submissive orientation) and has a tendency to respond with anxiety to stress $(1,5)$. P4 may be highly susceptible to depression, as he has experienced episodes in which he was abandoned by family, friends and acquaintances $(2,4,5,8)$. At times he is suffering from severe loneliness and longs for a new relationship $(3,7)$, but his fear of rejection is restraining him (6). An additional risk factor is his tendency to respond with intense grief after loss (1, 2, cf. prolonged grieving). P5 may be vulnerable to depression, as she has remained in a restrictive relationship for a long time (6) and is lacking the interpersonal skills to withstand the (subtle) bullying of colleagues (8, 9, cf. submissive personality). In addition, she has been enduring depressive feelings in her life for a long time $(6,7)$.

In the dismissive-avoidant cluster, several persons included a text referring to a 'lack of existential meaning' or 'dissatisfaction in work', possibly reflecting the consequences of a (long-term) one-sided investment in personal achievement. Besides these introjective topics, all five persons also disclosed anaclitic issues related to 'isolation and loneliness' (in past or present). Conspicuous were the discrepancies between text and affect, as some persons displayed a difficulty with allowing feelings of connection in texts concerning 'loss' or 'unfulfilled longing' (D2, D4), and several persons connected anger or annoyance $(-S)$ to texts in which they were clearly describing a dejected mood (D1, D3, D4, D5). Because of their cold-disconnected interpersonal orientation, according to the theory, dismissiveavoidant attached people are at risk to develop an introjective depression, involving "self-criticism, guilt, shame, worthlessness, and often a chronic fear of being criticized or disapproved" (Luyten, Blatt et al., 2005, p. 79). For some of the persons allocated to this cluster, we can find distinct traces of this introjective vulnerability. The first dismissiveavoidant person D1 (see Table 9) is clearly at risk to develop an introjective depression, because, although seemingly preferring solitude (3), he feels isolated and alienated from others and 'close' family $(4,5,6)$ (cf. cold-disconnected orientation), and displays a tendency to be extremely self-critical $(8,9)$ and critical towards others $(9,10)$. The few negative texts D2 has formulated seem to reveal some clues regarding introjective vulnerability. She (sometimes) experiences a lack of meaning in her life (1) and has been neglecting important friendships (5, cf. disconnected orientation). Moreover, in texts where she is clearly referring to loss, she is (defensively) not allowing any feelings of connection $(5,7$, 8 , cf. disconnected orientation), probably to avoid the pain that may be evoked by remembrances of lost relationships $(5,8)$. An extra risk factor may be the traumatic relationship with her father, which still resonates in her today life (3). Yet, the many $+\mathrm{O}$ texts (not presented here), in which she describes the satisfying and intimate relationships with her children and her family, point towards a sensitive side of her, which may counterbalance the introjective vulnerability. D3 formulated only few negative texts, making it difficult to find distinct introjective themes. One possible clue is the detached relationship with both of her parents (from early childhood on) (1, 2, 3, cf. disconnection). It appears that $\mathrm{D} 4$ may be at risk to develop an introjective depression,

\footnotetext{
${ }^{1}$ It should be mentioned that P1 formulated an atypical large number of $+\mathrm{S}$ valuations (See Table 8 ), which casts some doubt on the anaclitic vulnerability hypothesis for this person. However, although some of the $+\mathrm{S}$ texts were certainly indicative of autonomy or independence (e.g., "I am happy alone. I am satisfied and happy with how I am, with how I have arranged my life now"), other $+S$ texts revealed an 'external locus of self-hancement', many of which were related to his acting classes (e.g., "I have a very good feeling about the compliment of my drama teacher. It strengthens my belief that I can achieve my goal"). In addition, other $+\mathrm{S}$ valuations disclosed 'distortions' (e.g., "I was bullied at school. I remember that me and my brother were different, because we were wearing unusual clothes and didn't look as the other children at school"). Taken together, the +S texts do not seem to contradict the idea that this young male pre-dominantly displays a friendly-submissive interpersonal orientation.
} 
because he displays a high need for independence and control (in work) $(5,6,7$, cf. dominant-disconnected orientation), and has gone through a period of burn-out already (8). However, the ongoing longing for his unreachable ex-wife $(1,2,3)$, is indicating anaclitic vulnerability too (cf. prolonged grieving); affectively, he is nevertheless hardly allowing any feelings of connection in this longing for her. D5 may be at risk to develop depressive complaints, because she displays a self-critical perfectionistic attitude in her work $(4,6,8)$ and probably also in the care for her daughter $(1,5)$. Although she is obviously struggling with feelings of inferiority $(4,6)$, she's alluding indirectly to her independency (9) and superiority too (8, cf. dominant-disconnected orientation).

One of the crucial assumptions of the depression theories presented in this article (Blatt, 1974; Beck, 1983) is that depression typically originates from one-sided investment in either the striving for connection or the striving for self-definition, and neglect or defensive avoidance of the other. However, some persons may be extremely self-critical and also extraordinarily dependent on others (Blatt, 2004). Importantly, persons with this mixed anaclitic-introjective personality configuration display higher levels of psychopathology than persons with 'predominantly' anaclitic or introjective features. Blatt and Shahar (2005) present a complex diagnostic picture of a woman who was "head-strong and fiercely independent as well as achingly tender and vulnerable" (p. 154), highly competent and successful as an attorney, despite an extremely painful traumatic childhood and adolescence. They argue that her exaggerated emphasis on self-development, in part, served as a defense against the painful experience of 'unfulfilled longing for contact' with her (aloof and suicidal) mother. Conceptually, this mixed anaclitic-introjective type most closely resembles the fearful-avoidant attachment prototype, which is characterized by high anxiety (cf. dependency/sociotropy) and high avoidance (cf. self-criticism/autonomy). As alluded to previously, people with a fearfully avoidant style are caught up in an approach-avoidance conflict: they shun intimacy in relationships in order to preclude potential rejection, without really relinquishing their desire for acceptance from others. According to contemporary attachment theory (e.g., Liotti, 2006), fearful-avoidant or disorganized attached people, when feeling insecure and distressed, tend to display incoherent attachment behavior, that is a mixture of simultaneous or quickly alternating anxious and avoidant tendencies. For example, at one moment they may seek comfort and intimacy (cf. primary strategy) but, due to the anticipated or imagined rejection may abruptly deny these needs (i.e., distance themselves from others and avoid intimacy, cf. de-activation) and then suddenly resume the pursue for reassurance and support in an exaggerated clingy way (cf. hyperactivation). According to Simpson and Rholes (2002), fearfulavoidant attached persons " (...) may enact both [secondary] strategies in a haphazard, confused and chaotic manner (...) their behavior under stress may be an incoherent blend of contradictory, abortive approach/avoidance behaviors or perhaps paralyzed inaction or withdrawal" (p. 225). For this reason, some researchers regard the fearful-avoidant attachment style as an, essentially, dissociative form of attachment (Liotti, 2006). Therefore, the crucial defining feature of fearful-avoidant attachment is not so much the use of both (apparently incompatible) secondary strategies, but rather the incoherent entanglement in approach-avoidance conflicts and trance-like states that are a result of it. Research has supported the view that these kind of disturbances in the integrative processes of consciousness originate in traumatic childhood experiences with frightened and frightening caregivers (For a review, see Liotti, 2006).

Theoretically, fearful-avoidant attached people are at a high risk to develop depressive complaints, because of their

mixed anaclitic-introjective personality configuration. This double vulnerability implies that they value close relationships and excessively depend on the approval of others (and, therefore evade conflicts), but at the same time, as a consequence of their fragile trust in others tend to avoid intimacy in relationships (cf. approach-avoidance conflict). Hence, in theory, in their (close) interpersonal relationships they may, when feeling insecure or stressed, display an incoherent mix of alternating friendly-submissive and colddisconnected behaviors. Persons that display this kind of erratic behavior may be extra at risk to develop depressive complaints, because they are more likely to evoke disapproval and rejection from others. An additional risk factor is that people with this attached style are susceptible to dissociative states in which the integrative processes of consciousness are being disturbed. This detachment from reality and suppression of feelings is likely to impair coping with relational problems, increasing depressive feelings. The finding that most persons of the fearful-avoidant cluster formulated numerous -LL texts, supports the idea that this cluster is most vulnerable (see Study 2).

When looking at the valuations of the persons allocated to the fearful-avoidant cluster, some characteristic introjective themes came to light, viz. 'fear and avoidance of intimacy' and 'self-critical perfectionism'. Several persons included a text in which they referred to their tendency to suppress emotions (cf. dissociation), a theme that could not be found so explicitly in the texts of the preoccupied or dismissive-avoidant cluster. In addition, 'pleasing others' seemed the most prominent anaclitic theme in the texts. Noticeably, most persons of this cluster included a text in which they were referring to a (peculiar) problematic relationship with their 'mother'. The first fearful-avoidant attached person F1 (See Table 10) may be at risk to develop depressive complaints, because of a mix of introjective and anaclitic issues. She's profoundly perfectionistic in her work and private relationships (7, 8, cf. cold-disconnection), which is motivated by her need for validation/approval (7) and concern not to disappoint others $(9$, cf. friendly-submission). Furthermore, she indicates that she is used to suppressing her emotions, expecting them to be too overwhelming for herself and others (3, cf. dissociation). Accordingly, trusting no one and anticipating disapproval, she's reluctant to share her intimate feelings with others (5, cf. cold-disconnection). Her perfectionism, distrust in others and tendency to dissociate emotions may be a harmful mix indeed, making her susceptible for dejected emotions $(2,6)$. This vulnerability may be aggravated by the relationship with her rejecting mother: aged 53, she still wants her mother's acceptance (1), but instead, is condescendingly being reminded of her being a difficult child (4). In the few negative valuations of $\mathrm{F} 2$ there are clues that indicate predominantly introjective vulnerability. In several texts he expresses a 
'fear of intimacy' (2, 3, 4, cf. disconnection). As a result of his fear of sharing emotions with others, he may (sometimes) feel depressed, when he realizes that he is missing intimate bonds (5) and is not enjoying life (6). The few negative texts F3 has formulated seem to uncover some traces regarding introjective vulnerability. In the single $-\mathrm{O}$ valuation, she is revealing that she has serious issues with 'intimate relationships' (1, cf. disconnection), which seems related to her traumatic youth with her loveless parents $(2,3$, $4)$, especially with her frightening mother (2). In addition, she displays a rather perfectionistic attitude in her work (5) and is used not to count on support from others $(6$, cf. disconnection). In the texts of F4 there are clues that refer to introjective vulnerability. She is inclined to be extremely perfectionistic, i.e., habituated to exhausting her body $(5,7$, cf. dissociation) and accustomed to suppressing her emotions (8, cf. dissociation), which has led to a serious burnout period. She has a rather troublesome relationship with her mother, whom she would rather avoid (6, disconnection) and even doesn't want to think about (1, cf. dissociation). The negative valuations of F5 indicate predominantly anaclitic vulnerability. In some of the texts, she accentuates that, being afraid of rejection (9), she has a tendency to please others $(5,8)$. Accordingly, she is inclined to feel guilty, e.g., about not having intimate feelings for her father (6) or for not being able to care for her newborn daughter (cf. friendly-submission). In general, she is very concerned about the well-being of others $(2,3)$, which may be related to her childhood in which she was altruistically helping her mother (cf. parentification). An additional anaclitic risk factor is her inclination to respond with intense grief when being rejected $(4,10)$.

In the narrative accounts of the persons allocated to either the preoccupied, dismissive-avoidant or fearfulavoidant cluster, we came across various traces of anaclitic and introjective vulnerability. In the texts of the preoccupied cluster we found themes revealing a friendly-submissive interpersonal orientation, such as the excessive concern for others, (fear of) loss, (fear of) rejection, difficulty with being alone and overall fragility. Ideally, preoccupied clients are working at these kinds of issues during counselling. In SCM counselling these issues would probably be classified under the rubrics of 'dependency and lack of self-reliance' (many $+\mathrm{O}$ ) or 'depressive grieving' (many -O) (Hermans \& Hermans-Jansen, 1995). However, within the hybrid framework of attachment and depressive personality theory, additional overarching rubrics, such as the 'oversensitivity to others', 'excessive fear of rejection/abandonment' or 'difficulty with being alone' would possibly come into the picture (for counsellor and client). Consequently, in the initial diagnostic phase of counselling these kinds of additional themes could be helpful when setting and fine-tuning the goals of psychotherapy. Regarding counselling of preoccupied patients, Wallin (2007) contends that, because "[their] lives are fundamentally shaped by the fear of abandonment (...) [and their] greatest threats are separation, loss, and being alone (...)" (p. 225), psychotherapists should "offer them a relationship that presents an alternative to their hyperactivating strategy $(. .$.$) , in which [they] can come to count on$ the therapist's emotional availability and acceptance rather than feeling that they can obtain this quality of responsiveness only by defensively amplifying their affect and/or helplessness (...)" (p. 225).

In the texts of the dismissive-avoidant cluster, we identified themes indicating a cold-disconnected orientation, such as detachment/alienation, isolation, and self-critical perfectionism. Interestingly, some persons in this cluster had problems with allowing feelings of connection in texts about loss/unfulfilled longing. According to Wallin (2007) dismissing adults " $(\ldots)$ are reluctant to feel emotions that might spur them to connect deeply to others, and even more reluctant to express such emotions" (p. 211). Therefore, the experience of longing for an unreachable other $(-\mathrm{O})$ might be difficult to acknowledge and even more difficult to grasp at an emotional level. Additionally, several persons in the dismissive-avoidant cluster associated depressed texts with feelings of annoyance and anger $(-S)$, which indicates that it may be difficult for them to admit that one has so little help from others (cf. isolation) and so little control (cf. powerlessness) in life sometimes. By connecting high Self levels to these 'depressing texts', some illusory sense of control can be preserved, at least at an emotional level. SCM counsellors are being trained to be attentive to dysfunctional themes that are reminiscent of dismissive-avoidant attachment, such as 'other directed hostility' and 'depression with self-directed hostility' (Hermans \& Hermans-Jansen, 1995). However, according to the hybrid framework of attachment and depression theory, it seems that an SCM counsellor should also be attentive to texts revealing the 'distancing from others', 'avoidance of closeness' or 'need for control/independency'. According to Wallin (2007), dismissive-avoidant persons display a tendency to self-isolate in order to avoid being rejected and controlled: "He rejects, distances from, and tries to control his feelings" (p. 206), also in psychotherapy. Hence, consistent with their deactivating strategy, they tend to diminish the importance of others, including the psychotherapist. Therefore, "the central challenge is to enable the patient to allow the therapist to matter" (Wallin, 2007, p. 212). Ultimately, counselling of dismissive-avoidant persons should be aimed at connecting more deeply to others and the expression of intimate feelings. For a therapist, as Wallin (2007) argues, the key is to make a genuine emotional connection with a patient through 'empathic attunement' (i.e., focussing on nonverbal cues of a patient that reveal emotions) and '(subtle) confrontation' (i.e., disclosing how one feels as a counsellor in the communication, e.g., authentically disclosing irritation when a client has been implicitly provocative and devaluing for some time).

In the texts of the fearful-avoidant cluster, we encountered a mixture of introjective and anaclitic themes. The most striking and distinct features of this cluster were the 'fear and avoidance of intimacy' and concomitant 'suppression of emotions' (cf. dissociation). These features again draw attention to the fact that fearful-avoidant adults experience more emotional turmoil than preoccupied or dismissive-avoidant adults do (cf. Study 2). According to Mikulincer and Shaver (2007), the origin of disorganized attachment (i.e., the incoherent mix of neediness, detachment and dissociation) lies in traumatic early childhood ex- 
periences. They argue that insecure children at times experience parents as caring and available, at other times as frightened, and at still other times as frightening. This leads to multiple incompatible working models of the self (for example as a loved child and as a victim). As a consequence they are prone to deactivate the attachment system and cannot integrate all of their experiences into a coherent, meaningful inner life. We think that most persons in this cluster, were alluding to recollections of (childhood) experiences concerning serious neglect and rejection by (one of) their parents (Table 10: F1, F3, F4, F5), still having a profound influence on their current state of mind and relationships with others (including their parents). Admittedly, in the texts of the other two insecure clusters there were also clear signs of childhood experiences of neglect and rejection, but, overall, those of the fearful-avoidant cluster seem to be more poignant and detrimental. Some persons in this cluster were even explicitly referring to their tendency to dissociate or suppress emotions (Table 10: F1, F2, F4). In our view, texts referring to the dissociation or suppression of emotions may be a serious clue for a fearful-avoidant state of mind, and may indicate unresolved trauma. If there is (unresolved) trauma related to attachment or loss, strong emotional reactions (e.g., paralinguistic and somatic signals) will undoubtedly emerge in the direct communication between a counsellor and a client. These overwhelming, chaotic or trancelike states must be addressed in psychotherapy and seriously test the counsellor as someone with whom a client can feel safe. According to Wallin (2007), psychotherapy with unresolved patients, promoting the integration of dissociated experiences is the heart of the work. He argues that "(..) while for most patients the relationship with the therapist is a significant part of therapy, for patients who are unresolved the therapeutic relationship is the therapy" (pp. 243-244). In general, the main task of a counsellor is to provide "a safe haven and secure base from which [their patients] can begin to explore painful memories and emotions, characteristic but destructive defenses, and maladaptive beliefs and behaviors" (Mikulincer \& Shaver, 2007, p. 406), and to strengthen "the ability to make sense of oneself and others in terms of a coherent autobiographical and biographical narrative" (Allen \& Fonagy, in Wallin, 2007, p. 148). Detailed guidelines about how this may be achieved, is beyond the scope of this article. The clinical techniques and (exceptional) interpersonal skills that are needed for being a sensitive and responsive therapist, with the allied challenges related to transference and negative countertransference, are outlined in detail in more clinically oriented texts (Beier \& Young, 1984; Wallin, 2007; Mikulincer \& Shaver, 2007, Chapter 14).

In the present study, we investigated whether the introjective and anaclitic features as described by adult attachment theory and depression theory can be identified in a person's SCM self-narrative. The results of the first (quantitative) study indicated that the SCM affects (as experienced in recent daily life) reveal meaningful relationships with AAC attachment and personality subscales, but the relationships were not very strong. Nevertheless, the theoretical relationships were clearly 'visible' when the AAC variables were projected within the boundaries of a hexagon. A limitation of this first study was that people were being asked to connect affect terms to the standard valuation "How do you generally feel lately?", which doesn't necessarily evoke an attachment context. A standard valuation like, for example, "How do you generally feel in intimate relationships?" might be more appropriate. In the second (quantitative) study we detected meaningful patterns in the correlations between the percentages of valuation types (aggregated from each SCM grid) and the AAC (sub)scales. Cluster analysis supported the idea that, based on the profile of percentages in valuation types, a person can (provisionally) be classified as either secure, preoccupied, dismissiveavoidant, or fearful-avoidant, i.e., for assessing their predominant state of mind with respect to attachment. In the third (qualitative) study, we used this classification into attachment groups for the meticulous screening of the content of the $-\mathrm{S},-\mathrm{O}$ and $-\mathrm{LL}$ valuations of insecurely attached persons. This hermeneutic approach disclosed characteristic themes for each of the insecure attachment styles. Although a potential problem of cluster analysis is that cases may be forced into groups that are poorly delineated, in our data the four attachment groups were rather well separated (which was supported by the visual inspection of a two-dimensional PCA ordination, the stability of the solution [kappa], and an additional discriminant analysis).

A more fundamental methodological problem is the nonclinical nature of our research group, as the ethical guidelines stipulated that people with serious mental health issues were excluded from participation. In addition, most participants were predominantly higher-educated middle-aged women. So, strictly speaking, the results may not generalize to a (Dutch) clinical population. However, considering the nature of excerpts taken from the self-narratives of fifteen insecurely attached persons (in Study 3), several participants (particularly in the fearful-avoidant cluster) were unmistakably struggling with some serious psychological problems, which may be consistent with the notion that "most of us have islands of trauma and dissociation in our history (...)" (Wallin , 2007, p. 242). Additional research with clinical samples is needed, as persons who seek professional psychological help are more likely to display interpersonal problems related to anaclitic and introjective vulnerability. This brings us to the final methodological limitation of our study, in that 'trainees' were doing the SCM selfinvestigations. Although the five trainees were in the final master-phase of their psychology study, they had little experience with the Self-Confrontation Method and received only a relatively short training in this counselling method. Undoubtedly, this will have had an influence on the nature of the conversations, thus on the quality of the data itself. More experienced (SCM) practitioners, who are familiar to listen carefully (to painful experiences), are expected to be less reluctant to ask penetrating questions and more attentive to the critical aspects of a self-narrative.

Central to the Self-Confrontation Method, like other humanistic counselling methods, is the 'unique' person who is reflecting on his/her past and daily experiences. As illustrated above, the themes connected to the hybrid framework of attachment and depression theory, can be helpful in the initial phase when the focus lies on the identification of one or more guiding themes in a person's self-narrative, i.e., for delineating the main goals of psychotherapy. For that purpose, extra 'questions' could be added to the SCM in which a person is more explicitly invited to self-reflect about 
his/her intimate and attachment relationships. In our view, the SCM is ideally suited to be transformed to a truly 'attachment self-investigation method' (Cf. Main's Adult Attachment Interview; for a list of eligible questions, see Wallin, 2007, p. 29). Recently, scales have been developed for the idiographic assessment of attachment relationships (Van Geel, Houtmans \& Goodman, in prep; Goodman, 2018; see also Van Geel et al., 2011). These attachment scales, when combined with the SCM affect-scales, can offer a comprehensive and differentiated idiographic picture of (the problems associated with) past and present intimate relationships. It is our conviction, that by using the (accumulating) knowledge from the field of attachment and depression theory, idiographic personality research and narrative counselling methods can be enriched.

\section{ACKNOWLEDGEMENTS}

Parts of this article were presented at the $5^{\text {th }}$ International Conference on The (Non)Expression of Emotions in Health and Desease, held 23-25 October 2011, in Tilburg, The Netherlands. This research was supported by a grant from the (Dutch) Foundation for SCM-practitioners (Vereniging voor ZKM-beoefenaars). We are very grateful to Arjan Bentsink, Liduïn Hermeling, Tony Laumen, Eva Oudshoorn and Hans Tenten (also co-author of this article) for performing each twenty SCM self-investigations during their traineeship at the Department of Psychology of the Netherlands Open University.

\section{REFERENCES}

Bagby, R. M., Parker, J. D. A., Joffe, R. T., Schuller, D., \& Gilchrist, E. (1998). Confirmatory factor analysis of the revised Personal Style Inventory (PSI). Psychological Assessment, 5, 3143.

Bakan, D. (1966). The duality of human existence: An essay on psychology and religion. Oxford, England: Rand Mcnally.

Bartholomew, K. (1990). Avoidance of intimacy: An attachment perspective. Journal of Social and Personal Relationships, 7, 147-178.

Beck, A. T. (1983). Cognitive therapy of depression: New perspectives. In P. J. Clayton \& J. E. Barnett (Eds.), Treatment of depression: Old controversies and new approaches (pp. 265-290). New York: Raven Press.

Beier, E. G., \& Young, D. M. (1984). The silent language of psychotherapy $\left(2^{\text {nd }} E d\right)$. New York: Aldine Publishing Company.

Blatt, S. J. (1974). Levels of object representation in anaclitic and introjective depression. Psychoanalytic Study of the Child, 29, 107-157.

Blatt, S. J. (2004). Experiences of depression: Theoretical, clinical, and research perspectives Washington DC: American Psychological Association.

Blatt, S. J., \& Shahar, G. (2005). A dialetic model of personality development and psychopathology: Recent contributions to understanding and treatment depression. In J. Corveleyn, P. Luyten \& S. J. Blatt (Eds.), The theory and treatment of depression: Towards a dynamic interactionism model (pp. 137-162). Leuven/Mahwah, NJ: Leuven University Press/Lawrence Erlbaum Associates.

Blatt, S. J., \& Shichman, S. (1983). Two primary configurations of psychopathology. Psychoanalysis and Contemporary Thought, 6, 187-254.
Brennan, K. A., \& Shaver, P. R. (1998). Attachment styles and personality disorders: Their connections to each other and to parental divorce, parental death, and perceptions of parental caregiving. Journal of Personality, 66, 835-878.

Brennan, K. A., Clark, C. L., \& Shaver, P. R. (1998). Self-report measurement of adult attachment. In J. A. Simpson \& W. S. Rholes (Eds.), Attachment theory and close relationships (pp. 46-76). New York: The Guilford Press.

Desmet, M., Vanheule, S., Meganck, R., \& Verhaeghe, P. (2010). Reconstruction and validation of the Personal Style Inventory in a Flemish clinical and student sample. Psychological Reports, 106, 394-404.

Dunkley, D. M., Blankstein, K. R., \& Flett, G. L. (1997). Specific cognitive-personality vulnerability styles in depression and the five-factor model of personality. Personality and Individual Differences, 23, 1041-1053.

http://dx.doi.org/10.1016/S0191-8869(97)00079-2

Feeney, J. A., Noller, P., \& Hanrahan, M. (1994). Assessing adult attachment. In M. B. Sperling \& W. H. Berman (Eds.), Attachment in adults: Clinical and developmental perspectives (pp. 128-152). New York: Guilford Press.

Field, A. (2018). Discovering Statistics using IBM SPSS Statistics (5th ed.). London: Sage Publications.

Goodman (2018). Idiografisch assessment van hechtingsoriëntatie, affect en interpersoonlijk gedrag [Idiographic assessment of attachment orientation, affect and interpersonal behaviour]. (Master thesis, Department of Psychology and Educational Sciences, Netherlands Open University, Heerlen, The Netherlands).

Guisinger, S., \& Blatt, S. J. (1994). Individuality and Relatedness. Evolution of a Fundamental Dialectic. American Psychologist, 49, 104-111.

Helgeson, V. S. (1994). Relation of agency and communion to well-being: Evidence and potential explanations. Psychological Bulletin, 116, 412-428.

Hermans, H. J. M. (1976). Value areas and their development: Theory and method of self-confrontation. Amsterdam: Swets \& Zeitlinger.

Hermans, H. J. M. (1981). Persoonlijkheid en waardering [Personality and valuation] (vols. 1-3). Lisse, The Netherlands: Swets \& Zeitlinger.

Hermans, H. J. M., \& Hermans-Jansen, E. (1995). Self-narratives: The construction of meaning in psychotherapy. New York: Guilford.

Hermans, H. J. M., Hermans-Jansen, E., \& Van Gilst, W. (1985). De grondmotieven van het menselijk bestaan: Hun expressie in het persoonlijk waarderingsleven [The basic motives of human existence: Their expression in personal valuation]. Lisse: Swets $\&$ Zeitlinger.

Hofstra, J., Van Oudenhoven, J. P., \& Buunk, B. P. (2005). Attachment styles and majority members' attitudes towards adaptation strategies of immigrants. International Journal of Intercultural Relations, 29, 601-619.

Hopwood, C. J., Mulay, A. L., \& Waugh, M. H. (2019). The DSM5 Alternative Model for Personality Disorders: Integrating Multiple Paradigms of Personality Assessment ( $1^{\text {st }}$ Edition). London: Routledge

Kemmerer, D. D. (2006). Anaclitic and Introjective Personality Distinctions among Psychotherapy Outpatients: Examining Clinical Change across Baseline and Therapy Phases. PhD diss., University of Tennessee, 2006. https://trace.tennessee.edu/utk_graddiss/1809.

Levy, K. N., Johnson, B. N., Clouthier, T. L., Scala, J. W., \& Temes, C. M. (2015). An attachment theoretical framework for personality disorders. Canadian Psychology, 56, 197-207.

Liotti, G. (2006). A model of dissociation based on attachment theory and research. A model of dissociation based on attachment theory and research. Journal of Trauma and Dissociation, 7, 5573. 
Luyten, P., \& Blatt, S. J. (2012). Psychodynamic treatment of depression. Psychiatric Clinics of North America, 35, 111-129.

Luyten, P., Blatt, S. J., \& Corveleyn, J. (2005). The convergence among psychodynamic and cognitive-behavioral theories of depression: Theoretical overview. In J. Corveleyn, P. Luyten \& S. J. Blatt (Eds.), The theory and treatment of depression: Towards a dynamic interactionism model (pp. 67-94). Leuven/Mahwah, NJ: Leuven University Press/Lawrence Erlbaum Associates.

Luyten, P., Corveleyn, J., \& Blatt, S. J. (2005). The convergence among psychodynamic and cognitive-behavioral theories of depression: A critical overview of empirical research. In J. Corveleyn, P. Luyten \& S. J. Blatt (Eds.), The theory and treatment of depression: Towards a dynamic interactionism model (pp. 95135). Leuven/Mahwah, NJ: Leuven University Press/Lawrence Erlbaum Associates.

Luyten, P., Soenens, B., Vansteenkiste, M., \& Corveleyn, J. (2003). Personal Style Inventory (PSI): Dutch version. Leuven: Departement Psychologie, Centrum voor Psychoanalyse en Psychodynamische Psychologie.

McAdams, D. P. (1994). The person: An introduction to personality psychology. (2nd ed.) Fort Worth, TX: Harcourt Brace.

Mikulincer, M., \& Shaver, P. R. (2007). Attachment in adulthood: Structure, dynamics, and change New York: Guilford Press.

Nietzel, M. T., \& Harris, M. J. (1990). Relationship of dependency and achievement/autonomy to depression. Clinical Psychology Review, 10, 279-297. http://dx.doi.org/10.1016/0272-7358(90)90063-G

Ouimette, P. C., Klein, D. N., Anderson, R., Riso, L. P., \& Lizardi, H. (1994). Relationship of sociotropy/autonomy and dependency/self-criticism to DSM-III-R personality disorders. Journal of abnormal psychology, 103, 743-749.

Robins, C. J., Ladd, J., Welkowitz, J., Blaney, P. H., Diaz, R., \& Kutcher, G. (1994). The Personal Style Inventory: Preliminary validation studies of new measures of sociotropy and autonomy Journal of Psychopathology and Behavioral Assessment, 16, 277-300.

Simpson, J. A., \& Rholes, W. S. (2002). Fearful-avoidance, disorganization, and multiple working models: Some directions for future theory and research. Attachment and Human Development, 4, 223-229. http://dx.doi.org/10.1080/14616730210154207

Stein, H., Dawn Koontz, A., Fonagy, P., Allen, J. G., Fultz, J., Brethour Jr., Bevans, R. B. (2002). Adult attachment: What are the underlying dimensions? Psychology and Psychotherapy: Theory, Research and Practice, 75, 77-91.
Tabachnick, B. G., \& Fidell, L. S. (2001) Using Multivariate Statistics (4th ed.). Boston: Allyn and Bacon.

Tacq, J. (1997). Multivariate analysis techniques in social science research. London: Sage.

Van Geel, R. (2000). Agency and communion in self-narratives: A psychometric study of the self-confrontation method. Nijmegen: Nijmegen University Press.

Van Geel, R. (2011). Hexagon analysis of SCM data (SPSS syntax). Nijmegen: Netherlands Open University.

Van Geel, R., \& De Mey, H. (2003). Self, other, positive, and negative affect scales of the self-confrontation method: factorial structure and unidimensionality. Personality and Individual Differences, 35, 1833-1847.

Van Geel, R., \& De Mey, H. (2004). A theory-guided hexagonal representation of single valuation systems for use with Herman's self-confrontation method. Journal of Constructivist Psychology, 17, 85-104.

Van Geel, R., Houtmans, T., \& Goodman (in prep.). Idiographic assessment of attachment relationships (manuscript).

Van Geel, R., Houtmans, T., Verboon, P., \& Laumen, T. (2016). Integrating adult attachment scales and vulnerability factors in depression. International Journal of Personality Psychology, 2, 51-63.

Van Geel, R. De Munck, M.C., Biezepol, L., Werndly, I., \& Van den Boogaard. M. (2011). Idiografische assessment van hechtingsrelaties [Idiographic assessment of attachment relationships]. Narrator, 75, 19-27.

Van Oudenhoven, J. P., \& Hofstra, J. (2005). De Hechtingsstijllijst (HSL): Handleiding [The Attachment Style Questionnaire: Manual]. Groningen: Rijksuniversiteit Groningen.

Wallin, D. J. (2007). Attachment in Psychotherapy. New York: Guilford Press.

Westen, D., Nakash, O., Thomas, C., \& Bradley, R. (2006). Clinical assessment of attachment patterns and personality disorder in adolescents and adults. Journal of Consulting and Clinical Psychology, 74, 1065-1085.

Zuroff, D. C. (1994). Depressive personality styles and the fivefactor model of personality. Journal of Personality Assessment, 63, 453-472. http://dx.doi.org/10.1207/s15327752jpa6303_5
Received November 6, 2019 Accepted December 18, 2019 


\section{APPENDIX}

\section{SPSS syntax}

Classification method of SCM S-O-P-N profiles, based on the 30-list (Van Geel \& De Mey, 2003), and using the Conjunct classification method (cf. Finn Tschudi, 1995, personal communication).

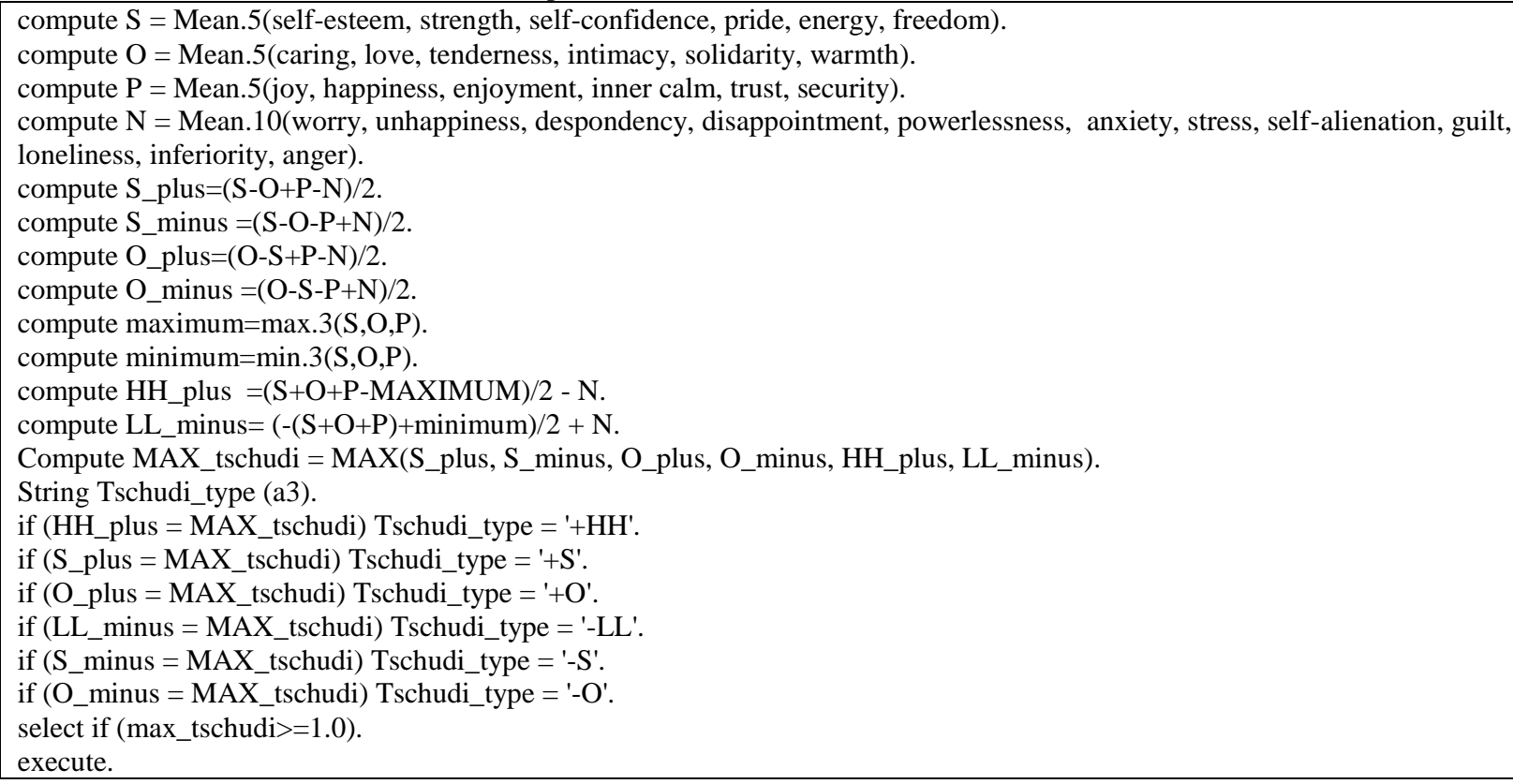

